\title{
HACIA UN MODELO TEÓRICO QUE DESCRIBA LA ESTRUCTURA SEMÁNTICA DE LOS SIGNIFICADOS DENOTATIVOS
}

\author{
JUAN LUIS JIMÉNEZ RUIZ \\ (Universidad de Alicante)
}

Escribir un trabajo sobre los problemas y métodos del análisis semántico de ninguna manera constituye una empresa de contornos fáciles de trazar: hasta puede sostenerse que esta disciplina recientemente anexada a la ciencia lingüística continúa buscando su metodología y su objeto. Esta comunicación es un intento de establecer una teoría lingüística sobre el significado que recoja y haga compatibles las generalizaciones sistemáticas de las distintas teorías lingüísticas sobre el mismo.

Entre los problemas que plantea el establecimiento de una reflexión coherente sobre el significado, el primero que surge, y que es necesario solventar, es el de la cuestión de los hechos que debe describir la teoría semántica. Sin lugar a dudas, la respuesta a esta pregunta puede variar substancialmente el resultado de nuestras investigaciones, puesto que en semántica, como en otras disciplinas, la decisión de incluir un determinado fenómeno dentro del campo de la teoría propia puede afectar al carácter de esa teoría en su totalidad' ${ }^{\prime}$ Por tanto, es necesario considerar algunos fenómenos designados, por lo general, como semánticos.

'Es cierto que, entre todas las ramas de la lingüística, la semántica es la que tiene, individualmente, más variados e íntimos contactos con otras disciplinas, de ahí que, como reconoce Ullmann, el descubrimiento de tendencias universales en esta área tendría repercusiones de largo alcanceen las esferas vecinas; cf. S. Ullmann, Lenguaje y estilo, Aguilar, Madrid, 1968, pág. 116. 


\section{SIGNIFICADO DEL HABLANTE Y SIGNIFICADO LINGÜÍSTICO. LA DESCRIPCIÓN Y LA EXPLICACIÓN COMO TÉCNICAS PREFERENTES.}

El primer fenómeno designado como semántico es, sin lugar a dudas, el de la significación.

\subsection{Designación. Significación. Significado. Sentido.}

El estudio funcional del vocabulario ${ }^{2}$ es la investigación del contenido léxico de las lenguas (del significado léxico). El término significado presupone una delimitación exacta frente a otros tipos de contenidos linguísticos; por ello, se ha generalizado la opinión de considerar la significación como un semema ligado a un significante. El problema surge cuando nos preguntamos si la unidad semántica tiene una existencia individual desde el punto de vista de la significación ${ }^{3}$. Para precisar este problema podemos basarnos en la distinción de Guillaume tomada por Fernández González"

- designación (Bezeichnung, designatio): es la capacidad que poseen los signos lingüísticos de referirse a realidades extralingüísticas, independientemente de la organización lingüística de esos signos (que, por supuesto, se da a través del significado); es decir, la referencia a la realidad entendida como extralingüística o a la realidad independientemente de su estructuración por medio de una lengua ${ }^{5}$. La designación se refiere a conceptos extensionalmente definidos, es decir, por enumeración de realidades ${ }^{6}$;

${ }^{2}$ Lexemática para Coseriu; cf. E. Coseriu, Gramática, semántica, universales, Gredos, Madrid, 1978, pág. 206.

${ }^{3}$ La respuesta ha sido muy variada, desde la conciliadora sostenida por Ullmann en su Senántica, para quien hay casos en los que el semantema tiene una existencia individual, hasta la contextualista de Rosetti, para quien la palabra sólo existe por el contexto; cf. A. Rosetti, «Le mot. Esquisse d'une théorie générale», $L L$ (1965), pp. 11-46.

${ }^{4}$ A. R. Fernández González et alii, «La significación» apud Introducción a la semántica, Cátedra, Madrid, 1977, pp. 36-43.

${ }^{5}$ Evidentemente, no está determinada sólo por el significado, sino también por principios generales del pensar y por la existencia del mundo; cf. E. Coseriu, Gramática..., pág. 207; y E. Coseriu, Principios de semántica estructural, Gredos, Madrid, 1977, pág. 187.

${ }^{6}$ Debemos recordar con E. Coseriu, Gramática..., pp. 135-140, que la significación es creación de la experiencia humana, lo que quiere decir que la lengua no es constatación, sino delimitación de fronteras dentro de lo experimentado. Esto obliga a distinguir dos enfoques:

- Enfoque extensional, que se refiere a la posibilidad de aplicar una definición a una serie de cosas. Se hace partiendo de la tealidad (de ahí que la designación se refiera a conceptos que han sido definidos sin tener en cuenta la lengua, partiendo de la realidad).

- Enfoque intensional, que se refiere a la posibilidad de aplicar una definición a los componentes que integran esa definición. Se fundamenta, por tanto, en una oposición y es, por ello, propio de la lengua.

Cf. al respecto, J. J. Katz, La filosofía del lenguaje, Martínez Roca, Barcelona, 1971, pp. 129 y ss.; J. Lyons, Semántica, Teide, Barcelona, 1980, pp. 153-154; H. Kubczak, Das Verhältnis von Intension und Extension als Sprachwissenschaftliches Problem, Narr, Tubinga, 1975; y H. Brekle, Sémantique, A. Colin, París, 1973, pp. 42-51; entre otros. 
- significación (meaning, Bedeutung): es la organización linguiística de esos signos, la estructuración opositiva que la lengua le da o, como afirma Coseriu, la significación se refiere a conceptos intensionalmente definidos, es decir, por rasgos distintivos;

- significado (sense, Sinn): es el contenido dado en y por una lengua como tal ${ }^{8}$;

- sentido: un semantema ofrece en la lengua uno o varios significados en potencia y en el discurso un único significado de efecto, al que llamaremos sentido. Éste es el contenido particular de una unidad textual que no coincide simplemente con el significado y la designación ${ }^{10}$. Sólo hay sentido en el acto de hablar en una situación determinada, pues el hablar crea precisamente un sentido válido y entendido intersubjetivamente ${ }^{11}$. Es, por tanto, el plano semántico propio y exclusivo del texto, determinado por medio del significado y de la designación ${ }^{12}$.

${ }^{7}$ Es, por tanto, un concepto metateórico superordinado. El significado de las expresiones lingüísticas se describe, pues, a partir de la noción de significación, en el sentido de que las palabras y otras partes del habla constituyen signos que, de alguna manera, significan o representan otras cosas; cf. J. Lyons, Semántica..., pág. 91.

8 Dentro del significado mismo pueden distinguirse distintos tipos; a saber, léxico, categorial, instrumental, estructural, óntico, etc. (cf. E. Coseriu, Gramática ..., pp. 136-137). Para una definıción relacional del significado pueden consultarse, entre otros, G. Wotjak, Investigaciones sobre la estructura del significado, Gredos, Madrid, 1979, pp. 32-95; H. Geckeler, Semántica estructural y teoría del campo léxico, Gredos, Madrid, 1971,pp. 42-97; K. Heger, «La semántica lingüística», Lexis, V, 2 (1981), pp. 5993; etc.

${ }^{9}$ Es evidente que la dicotomía lengua/habla no es una oposición material y deducida del objeto de la semántica, sino una oposición metodológica que se deduce de las diferentes posibilidades de encarar ese objeto. Su aplicación en la semántica puede verse en el trabajo de $\mathrm{K}$. Heger, «La sémantique et la dichotomie de langue et parole», TraLiLi, 7, I (1969), pp. 47-111 (hay traducción española en Teoría semántica II, Alcalá, Madrid, 1974, pp. 135-207).

${ }^{10}$ Cf. E. Coseriu, Gramática..., pág. 207.

11 Cf. B. Schlieben-Lange, Pragmática, Gredos, Madrid, 1987, pág. 97.

${ }^{12}$ A tal efecto debe considerarse la distinción de Frege entre sentido y referencia (el objeto al que una expresión signo se refiere o designa es su referencia y la peculiar manera de referirse a él es su sentido). Un enunciado tiene como referencia un valor veritativo, y como sentido, el pensamiento objetivo que encierra; cf. G. Frege, Estudios sobre semántica, Ariel, Barcelona, 1971, pp. 49-85. 
En el esquema de la figura $\mathrm{n}^{\mathrm{Q}} 1$ pueden observarse nuestras anteriores afirmaciones, sistematizadas por B. Pottier.

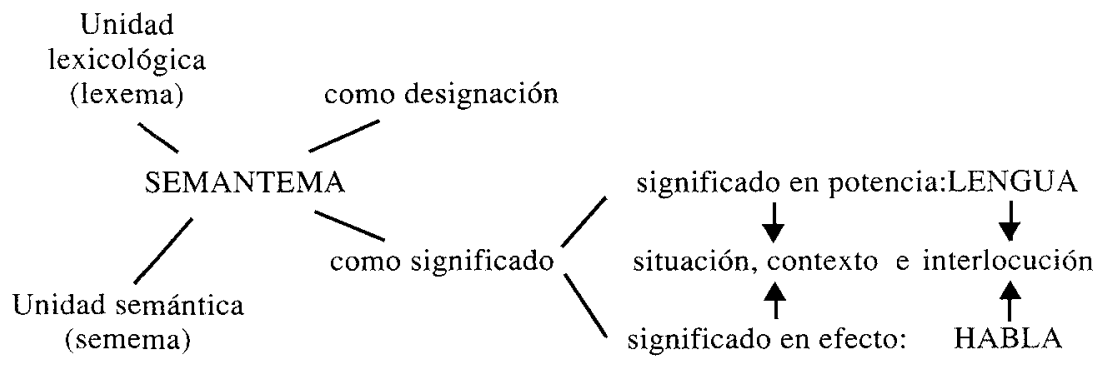

Fig. 1: El semantema como designación y como significado

Obsérvese que hemos integrado todas estas definiciones en la dicotomía lengua y habla, de manera que el trapecio metodológico de Heger ${ }^{i 3}$ podría representarse tal y como se refleja en la figura $\mathrm{n}^{\mathrm{o}} 2$.

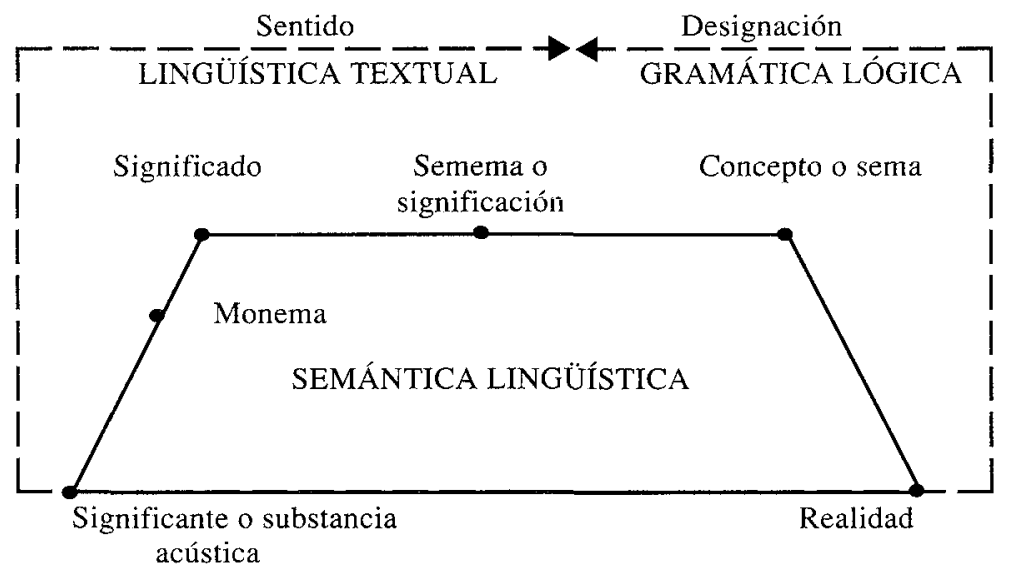

fig. 2: Lugar de los planteamientos teóricos propuestos en el trapecio de Heger.

${ }^{13}$ Cf. K. Heger, Teoría..., pp. 135-211. 
Podemos decir, pues, que la designación es la base semántica de referencia de la llamada lógica, así como de la gramática general o universal; el significado es la base semántica de la investigación de las lenguas; y el sentido la de la lingüística del texto ${ }^{14}$.

\subsection{Significado del hablante y significado lingüístico.}

La oposición significado/sentido resulta útil al permitirnos distinguir lo que podríamos denominar significado del hablante y significado linguístico ${ }^{15}$.

El significado lingüístico equivale a las posibilidades de significación de una unidad lingüística. El significado del hablante puede equipararse a lo que el emisor ha querido decir cuando ha producido un enunciado en una situación concreta ${ }^{16}$.

Se advierte subyacente el juego oposicional lengua/habla, que a su vez se basa en la distinción virtual/actual, abstracto/concreto ${ }^{17}$.

${ }^{14}$ E. Coseriu, Gramática..., pág. 136.

${ }^{15}$ La tesis que sustenta este trabajo se apoya en la distinción defendida por A. Akmajian et alii, Lingüística: una introducción al lenguaje y a la comunicación, Alianza Universidad, Madrid, 1984, pp. 275-313.

${ }^{16}$ Cf. K. Heger, Teoría..., pp. 155 y ss.

17 Según J. Lyons, «Semántica estructural y relaciones de sentido», apud Semántica..., pp. 235-315, todo fenómeno linguístico, toda actuación concreta, es la realización de una de las potencialidades que existen en la lengua, la cual, también hay que decirlo, sería un mero sistema abstracto sin estas realizaciones concretas. No podemos, consecuentemente, ignorar que la oposición entre significado lingüístico y del hablante no es tan rígida como pudiera pensarse a simple vista. Sin lugar a dudas, el hablante no significa con sus palabras nada que no esté (al menos en potencia) en la lengua. No obstante, y aunque la diferencia significado/sentido, como diferencia entre significado virtual y significado efectivo no se corresponde punto por punto con la diferencia entre significado del hablante y significado lingüístico, admitimos, si no su correspondencia exacta, sí cierta similitud que nos permitirá oponer el aspecto creador de la competencia chomskyana al carácter estático de la lengua saussureana y pasar a la construcción de los modelos que nos permitan describir el significado que las unidades linguísticas tienen dentro de esta lengua de carácter estático, y explicar el significado que las unidades lingüísticas han adquirido en la realización efectiva de la competencia lingüística.

A pesar del acercamiento entre el significado del hablante y la competencia, y el significado lingüístico y la lengua, no debe pensarse que la competencia ocupa (por aquello de la subjetividad) el espacio del habla (parole) de Saussure, siendo por ello un instrumento para describir concreciones; nada más lejos de la concepción chomskyana de la noción de competencia; cf. K. Bühler, Teoría del lenguaje, Revista de Occidente, Madrid, 1964, pp. 68 y ss.; L. Hjelmslev, Ensayos lingüústicos, Gredos, Madrid, 1972, pp. 90-106; y M. Crespillo, Historia y mito de la lingüistica transformatoria, Taurus, Madrid, 1986, pp. 112 y ss., y 166-182; entre otros. 
Si hablamos literalmente y queremos decir aquello que nuestras palabras significan, no habrá diferencias entre el significado lingüístico y el significado del hablante ${ }^{18}$, pero si no hablamos literalmente sî la habrá ${ }^{19}$. Según F. Lázaro Carreter $^{20}$, existen dos tipos fundamentales de lenguaje: el literal y el no literal. El primero es empleado en comunicaciones que deben ser descifradas en sus propios términos y que asídeben conservarse; frente al lenguaje no literal en el que ocurre todo lo contrario. Lo que en realidad distinguimos son dos formas con sus normas enfrentadas: la no literal y la literal. Entre ellas hay algo más que diferencias de grado; en el caso de los mensajes no literales, por poner un ejemplo, al emisor y al receptor les resulta indiferentes las características del cifrado (siempre que se asegure la comunicación), en los literales se presta mayor atención al proceso de cifrar; etc. Ruwet ${ }^{21}$ compara esta oposición con la dicotomía competencia y actuación, oponiendo el aspecto creador, dinámico de la competencia de Chomsky al carácter estático y taxonómico de la lengua de Saussure. Este

${ }^{18}$ Como hemos afirmado, el hablante no significa con sus palabras nada que no esté potencialmente en la lengua. Sin embargo, a veces el hablante puede utilizar las palabras para significar algo más de lo que éstas significan denotativamente en la lengua.

${ }^{19}$ Sin lugar a dudas, una concepción denotativa supone ignorar la constante generación de sentido para acentuar la ruptura entre palabra y realidad (F. Meix Izquierdo, Dialéctica..., pp. 148-159); de ahí que la oposición literal/no literal nos permita establecer, a su vez, la oposición entre lenguaje denotativo y lenguaje emotivo. No se trata de lenguajes distintos, sino de distintas realizaciones de un mismo lenguaje según el punto de vista adoptado: lectura literal (lo que nos permitirá realizar un estudio denotativo basándonos en un modelo al que llamamos lingüístico) y lectura no literal (lo que nos permitirá realizar un estudio emotivo basándonos en un modelo al que llamamos literario).

Pueden, sin embargo, objetarnos que lo emotivo de la lengua no necesariamente encuentra su explicación en un modelo literario, porque la emotividad afecta a muchas parcelas funcionales de las lenguas (no sólo a la lengua especializada de la literatura o de la poesía). Y estamos totalmente de acuerdo. Pero si tenemos en cuenta las palabras de M. Blanchot, El libro que vendrá, Monte Ávila, Caracas, 1972 , pág. 293, citadas por F. Wahl, ¿Qué es el estructuralismo? Filosofia, Losada, Buenos Aires, 1975, pág. 36 «el lenguaje está indeciso entre el ser que expresa haciéndolo desaparecer y la apariencia de ser para que la individualidad del sentido adquiera en él la figura», la literatura sería el movimiento con el que actuamos sobre estas diferencias (asî como la antropología o el psicoanálisis estudian los movimientos con que nos afectan). Ello justifica la elección de un modelo literario, aunque lo emotivo afecte, sin lugar a dudas, no sólo a la lengua especializada de la literatura.

${ }^{20}$ Cf. F. Lázaro Carreter, «El mensaje literal» apud Estudios de lingüística, Crítica, Barcelona, 1980, pp. 159 y ss.

${ }^{21}$ N. Ruwet, Introducción a la gramática generativa, Gredos, Madrid, 1978, pp. 50-51, 390-391. 
aspecto creador ${ }^{22}$ es una de las muchas formas que tiene un hablante ${ }^{23}$ a su disposición para no hablar literalmente (recuérdese que existen dos relaciones en el sistema lingüístico: la significación y la simbolización ${ }^{24}$ ).

\footnotetext{
${ }^{22}$ En la moderna teoría lingüística y del lenguaje verbal en particular, el término creatividad es usado en acepciones notablemente diversas. Nosotros lo hacemos en el sentido saussureano de parole, expresión individual, perpetua creación presente en cada realización sígnica. Las distintas concepciones de creatividad, a saber, la creatividad croceana o de la «parole», la chomskyana o de «langue», la humboldtiana o de «langage», la de los psicopedagogistas y, finalmente, la de los lógicos, aparecen claramente sistematizadas en T. de Mauro, Minisemántica, Gredos, Madrid, 1986, pp. 56-61; también es interesante al respecto M. Crespillo, Historia..., pp. 166 y ss., la exposición de J. C. Moreno, «Les tipologies holístiques», Lim., 5(1988), pp. 101-112, donde se precisa la importancia de la composicionalidad y la recurrencia en el desarrollo de la lingüística moderna, y el artículo de $\mathrm{H}$. B. Partee, «Compositionality» apud F. Landmann, Varieties of Formal Semantics, Foris, Dordrecht, 1984, pp. 281-311.

${ }^{23} \mathrm{El}$ que un discurso sea plurisignificativo no quiere decir que signifique cualquier cosa, sino que tiene un carácter textual que lo hace llegar a múltiples lectores, pero no debe olvidarse el carácter estructural de la obra, explicándola como un código que conocen tanto el hablante como el oyente. $\mathrm{Al}$ referimos al hablante nos situamos en el marco general de la teoría de la comunicación y lo usamos como sinónimo de emisor, autor, es decir, como el productor del texto cuyo significado vayamos a describir; cf. A. R. Fernández González et alii, Semántica..., pp. 122-126.

24 Desde que E. Cassirer conceptualizara al hombre como animal simbólico, debe precisarse la distancia que separa al signo del símbolo: el primero es un indicador concreto y físico del objeto, y el segundo es una zona (área) del mundo humano de la significación, una forma imaginaria de representación indirecta, subjetiva, psíquica, que reúne los aspectos particulares y subjetivos de la significación. De ahí la complejidad del símbolo y, consecuentemente, de la simbolización.

En el acto simbólico, el significante es la mitad visible del símbolo, y el significado la mitad oculta, hecho de aspectos no literales a la espera de un ejercicio hermenéutico (cf.J.Cuatrecasas, Lenguaje, semántica y campo simbólico, Paidós, Buenos Aires, 1972, pp. 32 y ss.). De hecho, la simbolización se fundamenta en la reflexividad del pensamiento humano, lo que le da un carácter consciente, arbitrario, voluntario, que viene determinado por su índole semirracional, por la intervención del intelecto en la creación lingüística, como unión de un elemento significante y un elemento significado, concebida esta unión como susceptible de disociabilidad (cf. M. J. Fernández Leboráns, Campo semántico y connotación, Planeta, Madrid, 1977, pp. 81 y ss.).

${ }^{25}$ Es la distinción típica de A. Greimas, Semántica estructural, Gredos, Madrid, 1977, pp. 54 y ss., entre virtualidad y manifestación, por lo demás, definitoria del método estructural, la que representamos (cf. también, R. Trujillo, Elementos de semántica lingüistica, Cátedra, Madrid, 1979, pp. 55 y ss.). Sobre las diferentes imterpretaciones del componente táctico-retórico y hermenéutico puede consultarse además J. Schmidt, Teoría deltexto, Cátedra, Madrid, 1978,pp.33-34; B.Schlieben-Lange, Pragmática...,pp.60-65; y J. Habermas, Theorie der Gesellschaft oder Sozialtecnologie, Francfort, 1971, pp. 101-141; entre otros.
} 
Esquemáticamente puede representarse tal y como aparece en la figura $n^{\circ} 3^{25}$ (adviértase la inserción de la dicotomía lengua/habla en el mecanismo de la comünicación ${ }^{26}$ ).

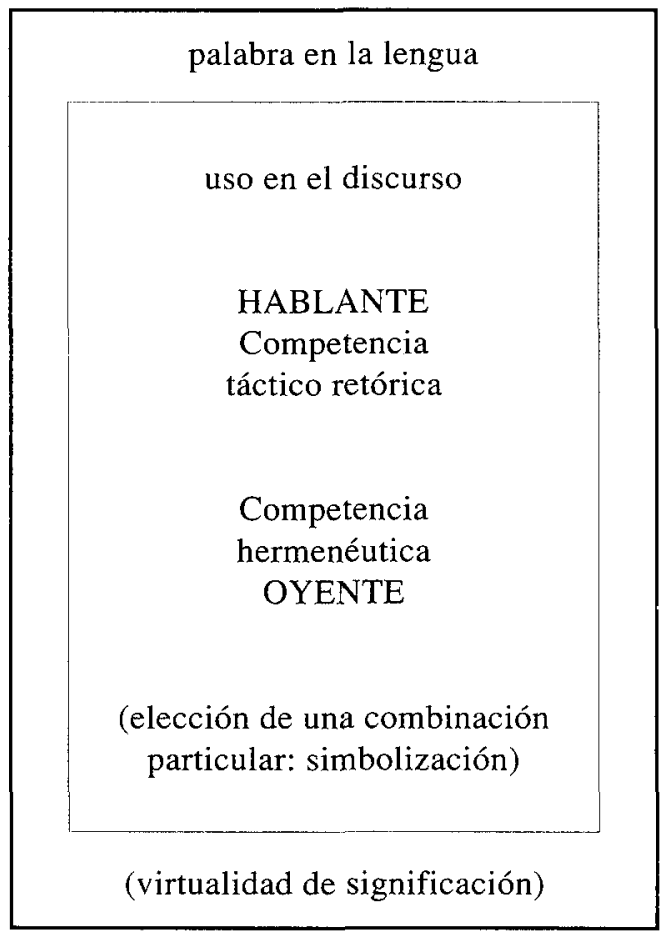

fig. 3: Significación y simbolización.

${ }^{20}$ Efectivamente, es el oyente el que interpreta la elección de una combinación particular hecha por el hablante (B. Pottier, Filología..., pp. 93 y ss.).

Existe, por tanto, una concepción psíquica bipolar que comprende dos términos: la forma significante y el concepto significado; y dos fases: la evocación del nombre por la cosa y de la cosa por el nombre. Este esquema se basa en relaciones muy complejas:

- relaciones entre concepto y cosa, que conciernen a la psicología, a la ontología (o conocimiento de la cosa) y a la epistemología (o crítica de ese conocimiento);

- relaciones entre concepto e imagen acústica. Es el problema de la significación, que concierne a la psicología lógica, y relaciones linguísticas (semántica);

- relaciones entre imagen acústica y forma. Problema de la fonación;

- transmisión y recepción del signo, que interesa a la acústica, teoría de la información, fonética y semántica; cf. P. Guiraud, «Estructura de la significación linguiística» apud La semántica, F.C.E., México, 1974, pp. 23-27. 
Obviamente, la gramática de una lengua no puede predecir cuándo los hablantes no hablan literalmente ${ }^{27}$. Consecuentemente, elaborar un modelo que describa el significado no literal o emotivo en el marco de una teoría lingüística sería caer en inconsistencias teóricas difícilmente superables.

Por tanto, el modelo lingüístico capaz de describir el significado de un texto literario o de un campo léxico ha de ser un objeto artificial destinado a reproducir en su técnica interna los objetos reales (el significado del texto o campo). Esta visión dicotómica nos lleva a plantearnos el problema de la postura que debe adoptar la teoría semántica ante el significado. Creemos que la teoría semántica debe estudiar ambos significados, adecuando los modelos al tipo de significado en cuestión ${ }^{28}$, tal y como recogemos en la figura $n^{2} 4^{29}$.

27 De hecho, como reconoce Todorov, «Sinécdoques» apud AAVV, Investigaciones retóricas II, Ediciones Buenos Aires, Barcelona, 1982, pp. 56-58, aunque la signifícación sólo puede ser literal pues las palabras no significan más que lo que significan y no hay otro modo de decir lo que dicen, en el lenguaje desviado poéticamente sí puede hablarse sin significar con las palabras lo que éstas significan en la lengua.

${ }^{28}$ Corresponde a la teoría lingüística dar cuenta del significado lingüístico y a la teoría literaria recoger el aspecto simbólico o significado no literal o emotivo. Al afirmar que la teoría literaria estudia lo que no es fácilmente sistematizable, negamos su valor científico con todas sus consecuencias. No creemos que la teoría literaria pueda llegar a ser nunca una ciencia; en el momento en que esto ocurriese la literatura dejaría de ser tal para ser otra cosa. Sin embargo, no negamos que en la literatura se unen técnica y belleza, lo que requiere para su comprensión un modelo formal y conceptual que intente explicar el significado de cada texto, de ahí que digamos, sin ningún otro motivo ulterior, que se ocupa de la actualización de cada individuo.

${ }^{29}$ Obsérvese la interferencia que existe entre el plano significativo y el simbólico. El hecho nos permite afirmar el carácter interdisciplinar del significado, siendo objeto a la vez de una teoría lingüística y literaria. Una vez más podemos afirmar que los límites entre el significado lingüístico y el del hablante no son muy tajantes. La teoría linguística que estudia la significación, da cuenta del significado linguístico en la lengua y del significado literal del hablante, junto a la teoría literaria (o semántica sintomática) que estudia la simbolización, dando cuenta del significado lingúístico idiolectal (que sería la modalidad lingüística de un individuo) y del significado del hablante no literal (cuando un individuo no quiere significar con sus palabras lo que éstas significan en la lengua, como ocurre en el uso literario del lenguaje). Por tanto, no debe pensarse, ni mucho menos, que la teoría lingüística se ocupe de la lengua y la teoría literaria del habla; es lo que muy acertadamente sostiene J. L. Cifuentes Honrubia, «Sobre la homologación de semiótica y pragmática: a propósito de un soneto de Góngora», ELUA, 6 (1990), pág. 147, cuando afirma que no debe confundirse la caracterización del acto linguístico que funciona dentro de un poema con el tipo especial de acción lingüística que constituye un poema; la teoría lingüística estudia los aspectos sistematizables (ya sean del significado lingüístico o del hablante) y la teoría literaria, aquellos que no son fácilmente sistematizables (los que responden a la actualización concreta de cada individuo del significado lingüístico).

Nosotros simplificaremos el problema y, por razones exclusivamente metodológicas (cf. J. L. Jiménez Ruiz, «El significado total del texto literario: ensayo metodológico», Quaderni di Letterature Iberiche e Iberoamericane, $\mathrm{n}^{\mathrm{a}} 14$, - en prensa-), y sin ninguna otra finalidad uiterior, adoptaremos un modelo lingüístico que estudie lo fácilmente sistematizable (el significado lingüístico), y un modelo literario que dé cuenta de lo no fácilmente sistematizable (el significado del hablante), plasmado en los textos literarios cuya estructura semántica pretendemos describir y explicar. 


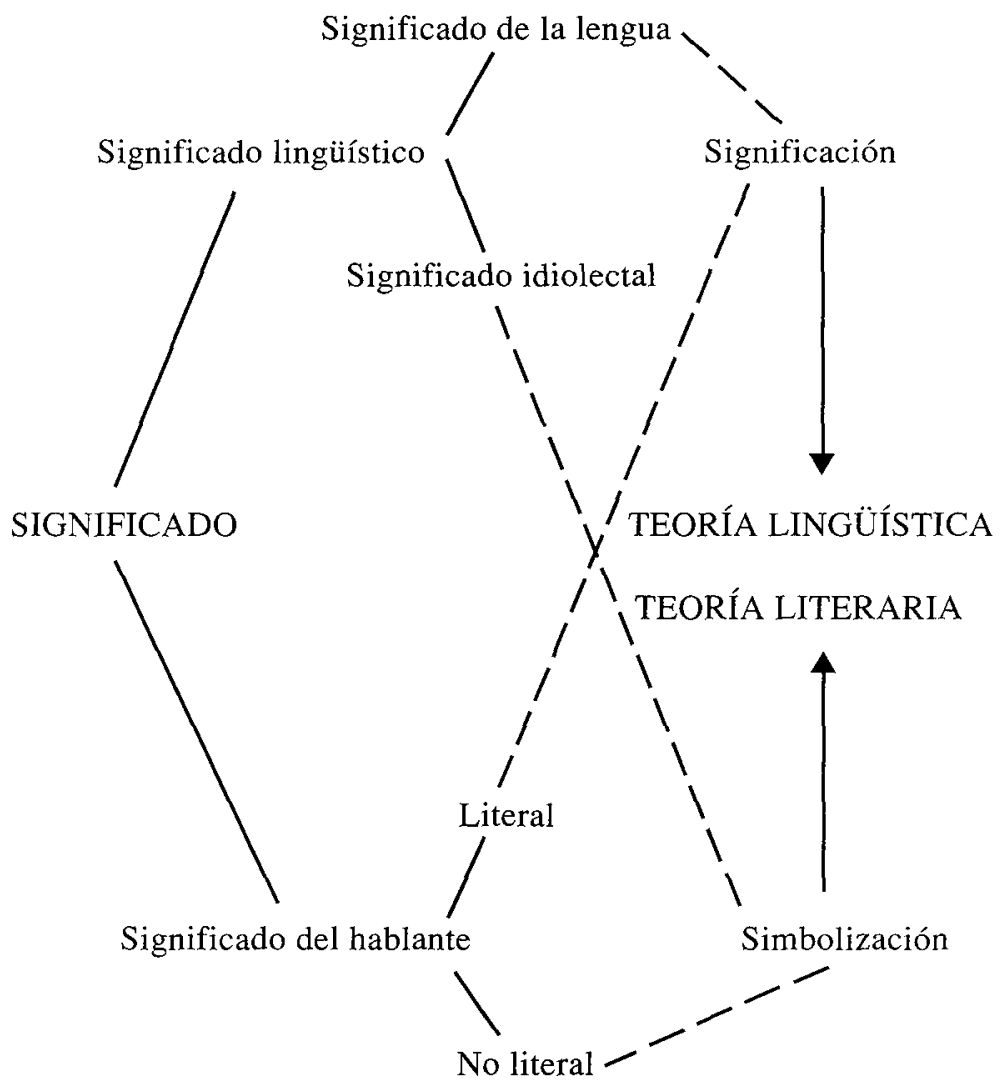

fig. 4: Posturas de las teorías semánticas ante el significado

Por tanto, postulamos no una rigidez en la oposición lengua/habla, sino una complementación; de ahí que el modelo teórico lingüístico describa la significación —dentro del proceso de semiosis, como virtualidad- (que recoge el significado de la lengua y el significado del hablante literal ${ }^{30}$ ) y el modelo literario explique la simbolización (que recoge el significado del hablante no literal y, al mismo tiempo, el significado idiolectal lingüístico) —obsérvese la figura $n^{0} 4$ - . De esta manera no existe una diferencia tajante entre significado idiolectal y significado del hablante; se trata, más bien de oposiciones en distintos niveles:

${ }^{30}$ Evidentemente, no utilizamos ahora el término significación como equivalente a semema; nos referimos al proceso de semiosis en el que la significación debe entenderse como virtualidad. 
lengua/habla $=$ significado lingǘstico/significado del hablante; $\mathrm{y}$ dentro del significado lingüístico, lo que pertenece a la lengua frente al uso individual = significado de la lengua/significado idiolectal ${ }^{31}$.

En resumidas cuentas, afirmamos lo siguiente:

- Existe un significado lingüístico y un significado del hablante que es resultado de la oposición metodológica lengua / habla de Saussure.

- La diferencia entre ambos significados se plasma en el aspecto creador del lenguaje.

- La teoría semántica debe dar cuenta de ambos significados.

- Tal teoría semántica estaría integrada, consecuentemente, por una teoría linguística que daría cuenta del significado linguístico (de lo sistemático); y por una teoría literaria o semántica sintomática que trataría de la simbolización o del significado emotivo (de lo que no es fácilmente sistematizable).

\subsection{La descripción y la explicación como técnicas preferentes.}

El siguiente paso en nuestras reflexiones consiste en delimitar los objetos que pertenecen al dominio de esta teoría lingüística capaz de dar cuenta del significado lingüístico:

- Todo lo que pueda servir de tertium comparationis, o sea, todo lo extramonolingual ${ }^{32}$.

- Todo lo característico de uno o varios de los diasistemas que han de ser comparados, o sea, todo lo monolingual que, junto con lo anterior, forma el dominio lingual ${ }^{33}$.

${ }^{31}$ La justificación metodológica de nuestra postura se entiende y justifica desde el momento en que afirmamos la no rigidez de la oposición lengua/habla (cf. K. Bühler, Teoría..., pp. 68 y ss.; E. Coseriu, Teoría del lenguaje y lingǘstica general, Gredos, Madrid, 1967, pp. 11 y ss.; L. Hjelmslev, Ensayos..., pp. 90-106; y K. Heger, Teoría ..., pág. 139; entre otros), así como que la lingüística debe dar cuenta del significado linguístico (aunque también recoge aspectos del habla - significado del hablante literal-), y la teoría literaria, entre otros, debe recoger el significado del hablante no literal (que se plasma fundamentalmente en los textos literarios), aunque también toma aspectos del significado linguístico el significado idiolectal-.

${ }^{32} \mathrm{~K}$. Heger, «Semántica...», pág. 77, pretende establecer el objeto de la semántica lingüística; para ello, distingue entre lo lingual y lo extralingual. Lo lingual sería el significante y el significado, frente a la realidad extralingüística, que sería lo extralingual. La semántica linguística tendría por objeto, consecuentemente, lo lingual. Pero, al ser éste, precisamente, el objeto de la lingüística, Heger introduce una serie de puntualizaciones. Partiendo de la diversidad de las lenguas, afirma que los objetos reales se comparan con sistemas de signos que se caracterizan por no ser linguales, sinomonolinguales, en el sentido de que dependen de la estructura de una lengua. Así, el elemento comparativo (que debe ser distinto del objeto al que se compara, que es lingual) no debe ser sólo extralingual sino extramonolingual. Por tanto, según Heger, la teoría semántica no debe descubrir sólo lo monolingual (característico de uno de los sistemas a comparar) sino también lo extramonolingual. Su unidad es el noema, que se introduce en el trapecio relacionándose con elementos monolinguales (semema) y extralinguales (la clase de los denotados); es extramonolingual por su independencia de las estructuras de una lengua.

${ }^{33}$ Heger pretende estudiar las tareas prioritarias de la linguíística por su contribución a la semántica. Para ello utiliza el término lingual y sus derivados en vez de lingüística y sus derivados. Al calificar lo lingual como lo que pertenece a la lengua, la linguística sería la disciplina que estudia la capacidad de hablar y, por tanto, quedaría excluida de la teoría semántica; cf. K. Heger, «Semántica...», pp. 74 y ss. 
Tal teoría semántica debe describir no sólo las características del significado, sino también las relaciones entre los mismos ${ }^{34}$. La propuesta hegeriana de incluir dentro de la teoría semántica lo extramonolingual nos permite introducir junto a la referencia lingüística, la referencia del hablante, es decir, los

realia denotados por el hablante al enunciar una expresión. Por lo general, la teoría semántica no ha prestado la misma atención a las relaciones referenciales que a las semánticas.

A continuación nos planteamos el problema de qué técnica debemos aplicar para la construcción de un modelo adecuado que dé cuenta de estos objetos. Para ello nos basamos en la oposición chomskyana descripción/explicación ${ }^{35}$.

Chomsky ${ }^{36}$, cuando justifica las gramáticas, nos dice que son descriptivamente adecuadas en la medida en que describen correctamente la competencia intrínseca del hablante nativo idealizado. Así, una teoría linguiística sería descriptivamente adecuada si hace posible una gramática descriptivamente adecuada. La adecuación explicativa se daría en la medida en que fuera una gramática descriptivamente adecuada en la que además se fundamenta esta adecuación ${ }^{37}$; sin lugar a dudas, los intentos de formular una teoría lingüística empíricamente adecuada deja la

${ }^{34}$ Además de describir las características de los significados, la teoría semántica debe describir las relaciones entre los mismos, entre otras, por las siguientes razones: por el carácter estructural de las significaciones; porque las significaciones particulares dependen de un cálculo de variantes que se deducen, lógicamente, de las relaciones posibles previstas en la descripción de la forma; y porque las significaciones generales dependen de valores que se derivan igualmente de la forma y definen las correlaciones posibles; cf. L. Hjelsmlev, Ensayos..., pp. 141-142.

${ }^{35}$ Las unidades llamadas descripción y explicación no son técnicas neutras porque están regidas por un mecanismo recóndito e inconsciente, caracterizado por la caducidad coyuntural. En el caso de los textos transformatorios, por poner un ejemplo, el modelo preferente puede definirse como la técnica que mejor elige los requisitos de adecuación, la que mejor determina los procedimientos para encontrar gramáticas adecuadas y la que arbitrá, en última instancia, si la descripción es un procedimiento mejor o peor que la explicación; cf. M. Crespillo, Lingüística..., pág. 48.

${ }^{36}$ Desde la constitución inicial de la gramática generativo transformatoria, N. Chomsky, Estructuras sintácticas, Siglo XXI, México, 1974, dedicó especial atención al problema de hallar una gramática adecuada y a los procedimientos necesarios para conseguir este objetivo. C. P. Otero, Introducción a la lingǘstica tranformatoria, Siglo XXI, México, 1970, expone claramente la trayectoria de estas ideas.

${ }^{37}$ Las gramáticas se justifican mediante los criterios adecuados con que se seleccionan, y éstos están constituidos por condiciones de adecuación externa, y por condiciones de generalidad. Las primeras constituyen criterios de adecuación débil pues conforme se realiza el proceso de aceptabilidad de las oraciones por parte del hablante nativo se admite que ciertas secuencias son claramente no-oracionales. Las condiciones de generalidad son criterios de adecuación fuerte pues son el primer fundamento serio con que contaron los textos transformatorios para construir una gramática universal; cf. J. Lyons, Chomsky, Grijalbo, Barcelona, 1974, pág. 44. Además, es interesante la recopilación de artículos que puede verse en J. A. Hawkins, Explaining Language Universals, B. Blackwell, Oxford, 1988, en los que examinan diversos enfoques para conseguir una adecuación explicativa de la lingüística. Las explicaciones van desde una perspectiva innatista a otra cognitiva, pasando por explicaciones semánticas y pragmáticas 
posibilidad de gramáticas incompatibles, dificultad que Chomsky intenta salvar añadiendo a la teoría unos procedimientos evaluativos ${ }^{38}$.

Antes de la gramática comparada del siglo XIX, en la descripción lingüística se utilizaba una serie de criterios heterogéneos; se intentaba explicar el origen del lenguaje según criterios teológicos,filosóficos e históricos.

A partir del siglo XIX, la descripción lingüística debe ser estrictamente lingüística. Esto plantea un problema: toda ciencia tiene un lenguaje específico y la lingüística debe utilizar su propio lenguaje para su metalenguaje; dificultad que Hjelmslev intentó superar creando un metalenguaje tomado de las propias ciencias $^{34}$, pero no tuvo éxito. Con todo, lo anterior nos permite ver el carácter eminentemente lingüístico de la descripción ${ }^{40}$ y basándonos en la oposición significado del hablante/significado linguístico aceptar tal dicotomía, como figura en el cuadro $n^{0} 5^{41}$.

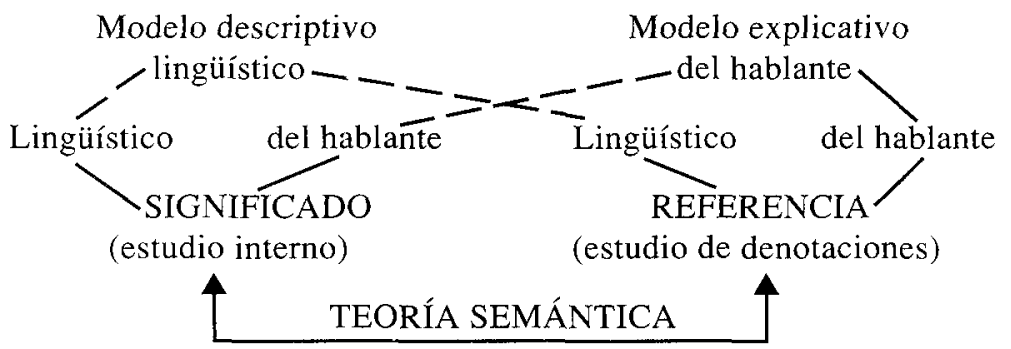

fig. 5: Lugar de la oposición descripción/explicación dentro de la teoría semántica.

${ }^{38}$ Los procedimientos propuestos por Chomsky para seleccionar una teoría adecuada que dé cuenta de la relación entre la teoría general de la estructura lingüística y una gramática particular constituye una de sus ideas fundamentales. El requisito más fuerte que debe imponerse es el procedimiento de descubrimiento de una gramática, mediante el cual la teoría debe proporcionar un método práctico y mecánico para construir realmente la gramática, dado un conjunto de locuciones. Un requisito menos fuerte es el procedimiento de decisión de gramáticas, por el que la teoría tiene que proporcionar un método para determinar si la gramática que se propone para un conjunto de enunciados es o no la mejor gramática de la lengua de la que se ha extraído dicho conjunto. El requisito más débil de todos es el procedimiento de evaluación de las gramáticas, por el que dado un corpus y propuestas dos gramáticas, la teoría dirá cuál es la mejor gramática de la lengua de la que se ha obtenido el corpus; cf. P. L. Garvin, On Linguistics Method, Mouton, La Haya, 1972, pp. 48-55; N. Chomsky y G. A. Miller, El análisis formal de las lenguas maternas, A.Corazón, Madrid, 1972; y N. Chomsky, Estructuras...,pp. 33 y ss. y Aspectos..., especialmente pp. 30-37 y 57-60, entre otros.

${ }^{39}$ L. Hjelmslev, Prolegómenos a una teoría del lenguaje, Gredos, Madrid, 1969.

4) D. Crystal, What is Linguistics?, Arnold, Londres, 1977, pp. 26-27.

41 Reiteramos, una vez más, lo dicho sobre la pareja descripción/explicación en su aplicación al estudio del significado. No mantenemos que la descripción sea más lingüística que la explicación; lo que presentamos es un proceso metodológico que se basa, en su primera fase, en la descripción de lo inmanente (el significado lingüístico), y en una segunda fase, en la explicación de lo trascendente (el significado del hablante). La razón se encuentra, fundamentalmente, en el ámbito de aplicación del modelo que proponemos: el mundo literario, que se nos ofrece como un primer significado linguístico que hay que trascender, para llegar a lo que el hablante (autor) ha querido decir con ello. 
P. Bourdieu ${ }^{42}$ hace una distinción entre una serie de conocimientos que vienen a apoyar nuestra tesis, desde el momento en que sirven para diferenciar entre un conocimiento objetivo de la lengua como sistema y un conocimiento subjetivo o fenomenológico. Ello nos permite elaborar unos modelos basados en ambos conocimientos: el objetivo, basado en una rigurosa descripción, y el subjetivo, centrado en la explicación particular e individual:

- conocimiento práctico, basado en la opinión que los individuos tienen sobre sus propias acciones. Se trata, por tanto, de un conocimiento ideológico y valorativo;

- conocimiento fenomenológico, que teoriza sobre el conocimiento práctico de un individuo tal y como se da;

- conocimiento objetivo: es un proceso que surge a partir de una ruptura epistemológica frente a los dos conocimientos anteriores; trata de construir el sistema de relaciones objetivas inconscientes e independientes del individuo;

- añade Bourdieu el conocimiento praxeológico, que es dialéctico e integrador (estructurador), y descubre las contradicciones del objetivismo.

Tales concepciones permiten la creación de dos escuelas ${ }^{43}$ : la llamada escuela objetivista, que defiende, entre otros principios, el carácter sistemático de la lengua, que estaría integrada por un conjunto de formas sometidas a una norma que es perentoria sobre los actos de carácter individual; la objetividad de las leyes linguísticas; el carácter inconsciente de las relaciones lingüísticas que no son asequibles a la conciencia individual; el hecho de que los fenómenos linguísticos no son de naturaleza ideológica, y, finalmente, la variabilidad de los actos individuales de habla, que son variaciones de estas formas sistemáticas.

Frente a la anterior, la escuela subjetivista defiende que el lenguaje es un proceso ininterrumpido de construcciones lingüísticas de la realidad que se materializa en actos individuales, que las leyes de la creación linguística son psicológicas, individuales, y la estructura del lenguaje está, en definitiva, en sí misma, $y$, finalmente, que el sistema es algo en continuo movimiento y que el objeto de atención deben ser las realizaciones individuales.

De esta forma tendríamos:

- un conocimiento objetivo de la lengua como sistema estable (se limita a la

${ }^{42}$ P. Bordieu, Esquisse d' une théorie de la pratique, Droz, Ginebra, 1972, pp. 162 y ss.

${ }^{43}$ Cf. M. Bakhtine, El signo ideológico y la filosofía del lenguaje, Nueva Visión, Buenos Aires, 1976.

${ }^{44}$ Por tanto, el excurso que presentamos, basado en Bordieu y Bakhtine, no debe entenderse como una justificación de la explicación del hablante como hecho o ámbito subjetivo. No es necesario decantarse por el subjetivismo exclusivamente para lo literario, frente al objetivismo exclusivamente para lo lingüístico. Como acabamos de decir, fundamentamos el estudio (sea lingüístico o literario) en el discurso, como elemento sintético de la dicotomía lengua/habla. Es una posición interaccionista (basada en el marxismo) que reúne y hace compatibles los planteamientos del objetivismo (abstracto) y del subjetivismo (individual). 
descripción para ser más riguroso y objetivo), dejando fuera las variaciones del habla;

- un conocimiento fenomenológico (subjetivo) del lenguaje como proceso ininterrumpido de construcciones lingüísticas de la realidad, que se materializa en actos individuales (explicativo, por tanto);

- y un conocimiento interaccionista (interactivo para Bakhtine, creador para Bourdieu), que fundamenta el estudio (sea linguístico o literario) en el discurso como elemento sintético de la dicotomía lengua/habla, y como elemento dinámico, energético y natural ${ }^{44}$.

\section{PROPUESTAS DE LA TEORÍA SEMÁNTICA.}

Llegados a este punto nos preguntamos qué debe hacer la teoría semántica y cómo debe hacerlo.

Creemos que la misión principal de una teoría sobre el significado es: primero, atribuir a cada semantema en la lengua las propiedades y relaciones semánticas que posea, así como definir dichas propiedades y relaciones; segundo, agrupar los semantemas según sus componentes de significado.

\subsection{Significado y referencia.}

En la historia de la semántica ha habido muchas directrices acerca del significado y la referencia. Históricamente, la noción más persistente sobre el significado suponía que éste era una especie de entidad o cosa ${ }^{45}$. Por ello decíamos que las palabras «tenían» un significado. Los objetos no existen en un espacio ideal sino que tienen una situacionalidad que implica un proceso hermenéutico. Consecuentemente, la significación de un signo está en relación ${ }^{46}$ :

- con la palabra tomada en un sentido general; se trata de una formalización en el nivel léxico;

- con la palabra en relación con un contexto; sería una formalización en el nivel sintagmático ${ }^{47}$.

${ }^{45}$ El carácter óntico del significado se debe, especialmente, a la teoría ontológica de Heidegger. Para él, el significado es una cosa cuyo carácter se propone descubrir. Para ello, en primer lugar, se pregunta en qué medida participa el significado de la naturaleza de la cosa y cita las tres teorías que se han dado al respecto:

- Teoría substancialista: la estructura de la cosa tiene un substrato permanente invisible y un conjunto de accidentes variables.

- Teoría sensualista: la cosa es sólo un conjunto de sensaciones.

- Teoría hilemórfica: la cosa es la unión de una materia con una forma, siendo ésta la que determina el ordenamiento de la materia.

Para Heidegger, el significado está en el lenguaje, donde se oculta la auténtica realidad del ser que somos. Se trata, por tanto, de una concepción trascendental del lenguaje; cf. M. Heidegger, Arte y poesía, F.C.E., México, 1982, pp. 41-55.

Vid. asimismo, E. Lledó, Filosofía y lenguaje, Ariel, Barcelona, 1970, pp. 117-133; A. Ortiz Osés, Antropología hermenéutica, Ricardo Aguilera, Madrid, 1973, pp. 33-38; R. J. Blasco, Lenguaje, filosofía y conocimiento, Ariel, Barcelona, 1973; etc.

46 Para lo que sigue puede consultarse F. Meix Izquierdo, Dialéctica..., pp. 131-135. 
Saussure, en el Curso $^{48}$ afirmaba que el signo lingüístico es una entidad bilateral (formada por un significante y un significado). Éstos son los lados del signo, no componentes. Consecuentemente, las concepciones derivadas de Saussure se oponen a las concepciones unilaterales del signo (que identifican el signo con el significante y tratan al significado como algo independiente). Sin embargo, en el modelo saussuriano no hay nada que corresponda a los objetos, relaciones, ni emisor ni receptor, porque para Saussure son realidades extralingüísticas.

C. Ogden y A. Richards ${ }^{49}$ fueron los primeros en introducir sistemáticamente el referente en el esquema triangular (tras las concepciones lógicas de los escolásticos y griegos). Para ellos, la relación entre signo y referente no es directa sino mediata, pues pasa por la referencia que puede ser considerada como la relación entre símbolo y referente o como entidad sui generis que permite ver dos relaciones: una entre símbolo y referencia, y otra entre referencia y referente.

K. Bühler ${ }^{50}$ representa las funciones del signo en el acto de la comunicación, sirviendo de base a todos los modelos de comunicación (obsérvese la visión esquemática de las distintas concepciones sobre el significado expuestas en la figura $\left.\mathrm{n}^{\circ} 6^{51}\right)$.

${ }^{47}$ La problemática del significado a su vez está muy unida a la problemática relacionada con la definición del signo lingüístico. La concepción sobre el significado atraviesa la cuestión de la función del signo lingüístico y de la relación del cuerpo del signo con lo designado o significado. Se trata, por tanto, de una definición relacional del significado, claramente expuesta en G. Wotjak, Investigaciones..., pp. $32-$ 95, donde se hace una clasificación de los tipos de significados.

48 F. de Saussure, Curso de lingüistica general, Losada, Buenos Aires, 1945, pp. 127-130.

${ }^{49}$ Cf. C. Ogden y A. Richards, El significado del significado, Paidós, Buenos Aires, 1964.

${ }^{50}$ K. Bühler, Teoría..., pp. 62-75.

${ }^{5 !}$ Los escolásticos afirmaban que se debía tener en cuenta el modo de ser, de significar y de decir; por eso se llamaban modalistas. No debemos olvidar que estudiaban los signos desde un punto de vista lógico, esto es, si los signos eran o no motivados por la realidad, etc. Ogden y Richards continúan el mismo planteamiento pero desde un punto de vista psicológico y lógico. Se trataba de ver la relación entre el pensamiento y el referente en términos de verdad, adecuación y corrección. Bühler completa esta concepción psicologista incluyendo en el modelo el resto de los elementos que intervienen en el proceso comunicativo; el panorama histórico de las distintas concepciones sobre el significado puede verse en $\mathrm{E}$. Lledó, Filosofía..., pp. 13-47.

Heger, en «Bases...», pp. 1-33, comenta el desarrollo del triángulo metodológico y su transformación en trapecio. Según Heger, el triángulo es útil didácticamente, pero presenta algunos fallos desde el punto de vista científico:

- ha dado un salto de la primera metalengua a la segunda:

- no soluciona el problema de la polisemia y la sinonimiá;

- el vértice superior confunde significado y concepto.

Para superar estas deficiencias, Heger transforma el triángulo en trapecio en el que:

- el lado izquierdo corresponde a las dos caras inseparables del signo linguíistico; simboliza la relación de consubstancialidad cuantitativa;

- el lado superior representa la consubstancialidad cualitativa; relaciona el signo, en cuanto significación, con los conceptos universales, y separa lo lingüístico de lo extralingüístico;

- el lado derecho es independiente de la estructura de una lenguá dada; pertenece a la mente, sea cual sea la lengua que se habla;

- la base del trapecio simboliza la arbitrariedad e inmotivación de la relación que representa. 


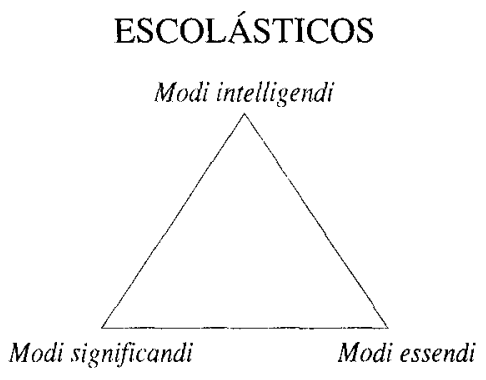

BÜHLER

Objetos y relaciones

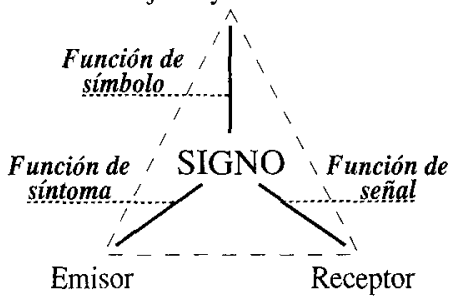

SAUSSURE

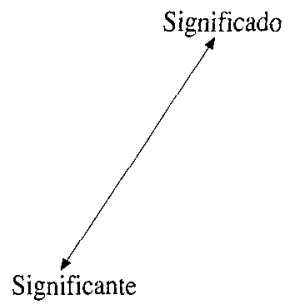

OGDEN y RICHARDS

Referencia

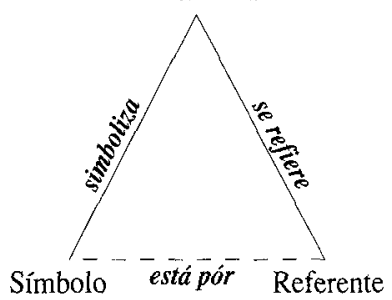

fig. 6: Visión esquemática de las distintas concepciones sobre el significado.

Sin embargo es a Heger a quien debemos la comparación global entre lo tres modelos de signos, tal y como aparece en la figura $n^{\circ} 7^{52}$.

\begin{tabular}{|c|c|c|c|c|}
\hline SAUSSURE & OGDEN Y RICHARD & BÜHLER & $\begin{array}{c}\text { SINTAXIS } \\
\text { SEMÁNTICA } \\
\text { PRAGMÁTICA }\end{array}$ & HEGER \\
\hline SIGNIFICANTE & SÍMBOLO & SIGNO & SINTAXIS & SIGNIFICANTE \\
\hline \multirow[b]{2}{*}{ SIGNIFICADO } & REFERENCIA & F. SIMBÓLICA & SEMÁNTICA & \multirow[b]{2}{*}{$\begin{array}{l}\text { SIGNIFICADO } \\
\text { Semema, } \\
\text { sema, noema }\end{array}$} \\
\hline & 0 & $\begin{array}{l}\text { F. SINTOMÁTTCA } \\
\text { F. SEÑALÉTICA }\end{array}$ & PRAGMÁTICA & \\
\hline \multirow{3}{*}{0} & REFERENTE & OBJETO & SEMÁNTICA & \multirow{3}{*}{$\begin{array}{l}\text { de denotados } \\
\text { del emisor } \\
\text { del receptor }\end{array}$} \\
\hline & & EMISOR & \multirow{2}{*}{ PRAGMÁTTCA } & \\
\hline & & RECEPTOR & & \\
\hline
\end{tabular}

fig. 7: Comparación entre los distintos planteamientos sobre el signo según Heger.

52 Debe tenerse en cuenta, para comprender bien el esquema:

- la distinción entre lo lingual y lo extralingual: lo lingual es el significante frente al $\mathrm{O}$; evidentemente, dentro de la semántica linguiística tiene prioridad lo lingual;

- según las funciones simbólica, sintomática y señalética, se produce la distinción entre semántica (que estudiaría la función simbólica) y pragmática (que estudiaría las funciones sintomática y señalética); cf. K. Heger, «Semántica...», pp. 59-93. 
Si seguimos avanzando en nuestras reflexiones, todavía podemos ir más adelante y preguntarnos qué tipo de cosa es el significado. Las diferentes respuestas nos dan una selección de las distintas concepciones del significado, y de los distintos tipos de teorías semánticas.

\subsubsection{Teoría referencial del significado.}

Sus seguidores se afianzan en la opinión de que el significado de cada expresión es el objeto efectivo o real a que ésta se refiere (su referente). Se basan, evidentemente, en la existencia de un objeto en sí con el que el signo lingüístico entabla contacto por medio de una vinculación externa o de un proceso asociativo de naturaleza interna.

Sin embargo, y aunque no afirman el carácter especular del significado, han recibido una serie de críticas, entre las cuales podemos destacar las siguientes: la adquisición del lenguaje por el niño requiere un discurso lingüístico que organice el mundo; el lenguaje hace posible la elaboración de los proyectos del hombre; no todas las expresiones con significado tienen un referente; que dos expresiones con la misma referencia debían tener el mismo significado y hay casos en que no lo tienen ${ }^{53}$.

A pesar de estas críticas, las orientaciones semánticas de tipo referencial han sido muy numerosas. Entre las principales corrientes podemos citar las teorías de la referencia indirecta, que entienden el significado como un proceso psicológico de carácter asociativo e interno al sujeto, a través del cual, el signo utilizado por éste se relaciona con el objeto significado. Algunos autores de esta tendencia son: Ogden y Richards ${ }^{54}$, Morris ${ }^{55}$, y Osgood ${ }^{56}$.

Para los defensores de las teorías de la referencia directa, el significado es una relación inmediata del signo con el objeto al que se refiere. Son partidarios de

53 Todo ello hizo necesario el desarrollo de los postulados de sentido, los cuales constituyen la aceptación de una organización lingüística (teniendo en cuenta que surgen en el interior de la semántica lógica); cf. F. Meix Izquierdo, Dialéctica..., pág. 21.

${ }^{54}$ Cf. C. Osgood, La medida del significado, Gredos, Madrid, 1976. Para este autor, el significado de un término no es más que un fragmento del proceso total de respuestas que suscita el referente del mismo. Entre sus postulados básicos podemos citar: la existencia del objeto, la vinculación entre éste y el sujeto como requisito para el aprendizaje lingüístico, y la primacía del mundo con respecto a la experiencia lingüística. Es interesante, además, la revisión crítica de la teoría osgoodniana y de sus aplicaciones que puede verse en R. Díaz Guerrero y M. Salas, El diferencial semántico del idioma español, Trillas, México, 1975, pp. 11-29 y 69-85.

${ }^{55}$ J. B. Watson, El conductismo, Paidós, Buenos Aires, 1976. Las palabras son subtitutos de los objetos y de las situaciones, como resultado de un proceso de condicionamiento verbal. El lenguaje viene a solucionar un problema de economía; el referente carece de historia y sentido, no existen en el sujeto pautas hereditarias de reacción ni significado alguno inherente a los objetos. Por tanto, objeto y sujeto son mundos aparte que sólo entran en contacto por medio de asociaciones condicionadas.

${ }^{56}$ L. Bloomfield, El lenguaje, Henry Halt and Company, Nueva York, 1964. Define la significación de una forma verbal por la situación en que se enuncia y por la respuesta suscitada en el receptor. La palabra posee un carácter instrumental, pues viene a colmar el vacío que existe entre los respectivos sistemas nerviosos de los interlocutores. Por tanto, el lenguaje se concibe como transmisión de informaciones entre dos sujetos sin tener en cuenta lo social (que sólo se ve como un conjunto de aprendizajes condicionados). 
estas teorías, entre otros, Watson ${ }^{57}$, Bloomfield ${ }^{58}$, Ryle $^{59}$, Skinner ${ }^{60}$, Quine ${ }^{61}$, etc.

${ }^{57}$ G. Ryle, El concepto de lo mental, Paidós, Buenos Aires, 1967. Es un filósofo de la escuela de Oxford, cercano al conductismo por sus posturas antimentalistas que demolen todos los conceptos mentales del lenguaje al uso intentando acabar con todo lo que pertenece al plano mental. La emoción es inaccesible a la observación directa científica, por ello, se usa para designar cosas muy distintas, y la emoción remite a objetos inexistentes, lo que crea enredos lógicos. Por todo lo dicho, se define antimentalista.

58 B. K. Skinner, Conducta verbal, Trillas, México, 1981. Pretende proporcionar un tratamiento causal o funcional satisfactorio de la conducta y, dentro de ésta, del comportamiento específicamente verbal. Para ello establece relaciones causales entre el sujeto y los objetos. El sujeto se concibe como un mecanismo de aprendizajes complejos que pueden ser renovados por nuevas asociaciones. Lo interior es rechazado; de ahí que explique la relación sujeto-objeto mediante reflejos establecidos de antemano por condicionamientos y rechace las ideas mentalistas ya que tales posiciones habrían llevado a postular la existencia de lo lingüístico al margen de la conducta. De esta forma, el lenguaje ideal sería el que reflejara fielmente los objetos. Las palabras deben diferir entre sí en la medida en que difieren sus referentes.

${ }^{59}$ W. O. Quine, Las raíces de la referencia, Revista de Occidente, Madrid, 1977. Postula la existencia independiente de los objetos (aunque no rechaza los conceptos mentales). Para él, el lenguaje no reproduce la realidad misma sino que posibilita que el sujeto la configure. La obra de Quine constituye el punto de referencia fundamental de la polémica en torno a la admisibilidad científica de los conceptos semánticos fundamentales. Las tesis de Quine, que tuvieron un impacto extraordinario entre filósofos y lingüistas interesados en los problemas semánticos, venían a plantear la disyuntiva siguiente: o se admite la imposibilidad de que la semántica pueda aspirar a presentarse como una ciencia empíricamente respetable, o bien se ofrece una refutación de las críticas quineanas a las nociones de sinonimia, intensión, sentido, etc. Los filósofos del lenguaje pasaron a dividirse, en parte debido a la obra de Quine, en dos grupos: el extensionalista, integrado por los que admiten las estrechas limitaciones establecidas por Quine para la semántica, y el intensionalista, formado por los que afirman la ineludibilidad para la filosofía del lenguaje de las nociones impugnadas por Quine; cf. M. Hernández Iglesias, La semántica de Davidson, Visor, Madrid, 1990, pág. 18.

${ }^{60}$ Para el mentalismo, las palabras no son símbolos de percepciones aisladas, sino símbolos de conceptos. Por ello, el lenguaje es concebido como un vehículo de transmisión del pensamiento. Este vehículo puede analizarse activamente (en el intuicionismo) o pasivamente (en los estructuralismos). La identificación entre lenguaje y pensamiento es más bien un presupuesto materialista (que Marx y Engels dejan claro en la Ideología alemana). Por otra parte, la posición de los filósofos del lenguaje alemanes (Humboldt, Herder, Harmann) aunque implica una cierta coincidencia entre lenguaje y Weltanschauung, está teñida de un claro relativismo linguíístico. Esta identidad reproduce en el pensamiento la unidad de la razón y el lenguaje como medio de este postulado.

La identidad origina la hipótesis de Sapir-Whorf o teoría de la relatividad linguiística: la cultura (aquello que la sociedad hace o piensa) no coincide con la lengua que dicha cultura utiliza como medio de expresión. Nos encontramosen un nuevo principio de la relatividad que sostiene que todos los observadores no son conducidos por la misma evidencia física o la misma representación del universo, a menos que sus bases linguiísticas sean similares o puedan ser calibradas de alguna manera (cf. B. L. Whorf, Lenguaje, pensamiento y realidad, Seix Barral, Barcelona, 1963, pp. 212 y ss.). Así, la teoría de la relatividad linguística defiende que el lenguaje es un factor creativo que modifica la visión del munđo de los hablantes de acuerdo con la categoría de relación con que se caracteriza el pensamiento.

A pesar de las críticas recibidas por Whorf basadas principalmente en el hecho de que toda su teoría se centró en la estructura gramatical y sobre las categorías que esta estructura impone en el pensamiento y en el comportamiento (cf. S. Ullmann, Lenguaje..., pp. 256-257), sin tener en cuenta que el vocabulario posee también una organización y una estructura propias; y en el hecho de que las estructuras gramaticales básicas de una lengua permanecen constantes a lo largo de su desarrollo durante largos períodos de tiempo en los que la cultura cambia radicalmente (cf. F. v. Kutschera, Filosofía del lenguaje, Gredos, Madrid, 1979, pág 354); esta hipótesis es la primera reformulación en nuestro siglo de la identidad racionalista lenguaje y pensamiento; al respecto es interesante G. A. Miller, Habla..., pp. 135-138; G. A. Miller, Lenguaje y comunicación, Amorrortu, Buenos Aires, 1979, pp. 186 y ss.; G.A. Gutiérrez López, Estructura del lenguaje y conocimiento. Hacia una epistemología de la semiótica, Fragua, Madrid, 1975, pp. 147-150; M. Casado Valverde, Lenguaje y cultura, Síntesis, Madrid, 1988, pp. 53 y ss.; A. Schaff, Lenguaje y conocimiento, Grijalbo, México, 1977, pp. 85-138; entre otros.

${ }^{61}$ F. Meix Izquierdo, Dialéctica..., pág. 131. 


\subsubsection{Teoría mentalista.}

Podría decirse que el significado no es un objeto real, sino mental ${ }^{12}$. El significado, así presentado, sería una idea asociada a un significante en la mente de los hablantes, un reflejo perceptivo desprovisto de toda intencionalidad, un esquema o pauta de relación del individuo con su mundo, entendiéndose la percepción no como un conjunto de percepciones aisladas sino como una sensación del cuerpo con el ambiente ${ }^{63}$.

Las raíces de estas imágenes psíquicas están en la abstracción pues consiste en una posibilidad de selección entre las distintas que el medio posee. De esta abstracción selectiva le viene su sentido, quedando así definida la percepción humana como un fenómeno significativo ${ }^{64}$.

Con todo, puede objetarse a esta teoría la vaguedad de la noción de idea, hecho que impide someterla a prueba; hace asimismo predicciones falsas, pues las ideas son distintas para cada individuo ${ }^{65}$.

${ }^{62}$ Las relaciones entre discurso lingüístico y percepción aparecen desarrolladas en nuestro trabajo «Notas para una teoría de la explicación del significado connotativo», Analecta Malacitana, IX, 2 (1896), pp. 407-419.

${ }^{63}$ Efectivamente, cada individuo tiene su propio concepto de las cosas y, aunque se den rasgos cn común, se trata de conceptos variables, cambiantes. Sin embargo, esto no es un obstáculo para el desarrollo de una teoría objetiva.

Heger (en «Bases...» apud Teoría..., pp. 1-33) afirma que el mundo de los conceptos es el mismo para todas las lenguas, pero diferente para cada individuo.

El problema que se plantea es cómo estructurar este mundo. B. Pottier, en «La semántica y los criterios funcionales» apud Filología..., pp. 93 y ss., hace la distinción entre el ámbito nocional, que sería la masa amorfa del pensamiento que decía Hjelmslev, y el campo lexical, que sería la capacidad que tiene una lengua para estructurar el ámbito nocional.

${ }^{64}$ Para B. Russell, el lenguaje estaría constituido por proposiciones moleculares compuestas de proposiciones atómicas, que serian los elementos básicos del lenguaje, y por proposiciones atómicas, formadas por nombres propios, que tienen carácter de índice, de alusión deíctica al mundo del referente.

Puede apreciarse que se trata de una concepción realista pues reconoce la existencia del mundo del objeto al margen de la presencia de cualquier sujeto cognoscente; cf. F. Meix Izquierdo, Dialéctica a.., pp. 36-38.

${ }^{6.5}$ Su concepción de denomina teoría de la imagen. Parte de la identificación y reconocimiento de los hechos como constitutivos fundamentales del mundo. Ambos tienen el mismo ámbito y límites. Los nombres significan el objeto al que se refieren, pero no son simples reflejos de dicho referente. Tienen una estructura lógica representada en la proposición (se pasa de una concepción denotacional del significado a una más amplia, adjudicando a la proposición el sentido en el conjunto de la frase). Por tanto, la proposición tiene un carácter componencial que pretende dar un nuevo sentido con expresiones viejas. Surge, entonces, la teoría del mostrar: la función más importante de la proposición es darnos a conocer la estructura de lo real, y esto no lo puede realizar por medio del decir. La proposición no puede hablar de su estructura, sólo mostrarla. Por tanto, el lenguaje sólo puede mostrar la estructura del mundo. Para Wittgenstein, los signos primitivos no pueden entenderse si no es en el conjunto de la frase, pero, a su vez, ésta sólo es inteligible si se conoce el significado de los elementos que la constituyen (cf. F. Meix Izquierdo, Dialéctica..., pp. 38-43; además, sobre la teoría del significado de Wittgenstein es interesante J. L.Prades Celma, Wittgenstein, mundo y lenguaje, Cincel, Madrid, 1990, pp. 55-84).

Por ello, Schaff interpreta el significado como una relación humana entre los hablantes, y no como un objeto; así, el sentido de la proposición es mostrado, depende de lo que se dice, y requiere el conocimiento de los signos que la componen, aunque no puede reducirse a ellos (cf. A. Schaff, Lenguaje..., pp. 170 y ss.; y J. Katz, Filosofía..., pp. 67 y ss.).

Greimas se lanza contra el carácter unidimensional del lenguaje y nos habla de un sistema con varios niveles de sentido, de un lenguaje simbólico en el que las dimensiones de lo real se consideren en torno al signo material. Así, la lógica depende del lenguaje y consiste en una sistematización que organiza la captación de lo real (cf. A. J. Greimas, Semántica..., pág. 55).

Como puede deducirse, el significado de una palabra, por tanto, es su uso. En el texto se esconden el funcionamiento y el uso, las reglas del juego lingüístico. Es lo que se conoce como el problema lógico de Wittgenstein, que atañe a las condiciones necesarias para que en las combinaciones de símbolos se dé el sentido a partirde la unicidad de referentes (cf. A. Ortiz Osés, Hermenéutica..., pp. 33-38). 


\subsubsection{Teoría del significado como uso.}

Afirman que el significado de la palabra es el uso que ésta tiene, encontrándose escondido en el texto el funcionamiento y el uso, las reglas del juego lingüístico. Entre otros, esta teoría fue defendida por Russell ${ }^{66}$, el $2^{\circ}$ Wittgenstein ${ }^{67}$, Grice y Schiffers ${ }^{68}$.

Lo que apreciamos claramente tras este breve panorama es la confusión de las distintas teorías acerca de lo que es el significado ${ }^{69}$. Consecuentemente, nuestra postura es la siguiente:

- la significación o referencia de un signo está en relación con la palabra en sentido general (significado denotativo) o en relación con un contexto (del que puede emanar, en algunos casos, su significado emotivo ${ }^{70}$ );

- por tanto, situaremos la teoría semántica en el marco de una teoría lingüística y literaria;

- la teoría linguística debe describir el significado denotativo;

- la teoría literaria debe explicar el significado emotivo ${ }^{71}$.

\subsection{La descripción del significado lingüístico.}

En el marco de la teoría lingüística, los trabajos de Ullmann ${ }^{72}$ son un ejemplo

${ }^{66}$ Fundamentalmente, los trabajos en los que Grice y Schiffers han desarrollado sus teorías aparecen citados en AAVV, Introducción a la lingüística matemática, Teide, Barcelona, 1978, pág. 213.

${ }^{67}$ La razón se debe a lo que Rorty llama dialéctica entre filosofía del lenguaje ideal y filosofía del lenguaje ordinario. Al respecto puede verse R. Rorty, El giro lingüístico, Paidós, Buenos Aires, 1990, pp. 76 y ss.

${ }^{68}$ Por ejemplo, en el caso del verbo abrir, las diferencias semánticas que pueden producirse en sus distintas actualizaciones contextuales (se me abren las carnes al verlo así; se me abre la puerta y hay corriente; ; me abro, chicos!) no son emotivas; son sencillamente efecto de la polisemia de abrirse. Por ello, no debe suponerse la identificación entre el significado contextual (sema nuclear + semas contextuales, según Greimas, por ejemplo) y significado emotivo; el significado connotado (del que el emotivo podría quizás ser un tipo) estaría en relación de especie a género con el contextual.

${ }^{69}$ La relación sígnica es la que se establece entre el significante y el significado; la relación discursiva la que se establece entre los signos que constituyen el discurso. Pues bien, el estudio del signo literario consiste en el análisis de las relaciones entre las dos relaciones; cf.C. Segre, Semióticafilológica, Universidad de Murcia, Murcia, 1990, pp. 41 y ss.

Esto no significa que se deba partir de pirámides conceptuales distintas, una linguística o denotativa y otra emotiva o literaria. Se trata más bien de la existencia de semas o haces de semas específicos construidos en tradiciones literarias también específicas que deben ser tenidos en cuenta en el modelo que proponemos, ya que reúnen aspectos relevantes de una concepción del mundo que puede explicar mejor el significado del discurso que pretendemos decribir.

${ }^{70}$ Entre otros, nos referimos a The Principles of Semantics, B. Blackwell, Oxford, 1951; Semántica...; Lenguaje...; $\mathrm{y}$ «The concept of meaning in Linguistics», Archivum Linguisticum, I, 8 (1956), pp. 12-20.

${ }^{71}$ Cf. H. Geckeler, «Sobre el estado de investigación en semántica» apud Sentántica..., pp. 17-42.

72 Cf. G. Leech, «Componentes y contraposiciones de significados» apud Semántica, Alianza Universidad, Madrid, 1977, pp. 115-146. Se trata de los procedimientos para descubrir la significación partiendo de la descomposición del sentido de una palabra en rasgos distintivos mínimos que se contraponen. 
patente del intento de salvar la confusión que existía en el campo del significado. Se produce, así, un viraje hacia una semántica descriptiva y estructural ${ }^{73}$. Desde este punto de vista, el análisis del significado se concibió como la descomposición del sentido de una paläbra en rasgos distintivos mínimos o componentes que se contraponen unos a otros ${ }^{74}$. Tales definiciones pueden hacerse mediante combinaciones de rasgos. Este método se desarrolló, en primer lugar, en la lingüística antropológica para estudiar las estructuras de parentes $\mathrm{Co}^{75}$. A partir de entonces tuvo un gran auge aunque, todo hay que decirlo, tampoco han faltado las críticas a tal tipo de análisis ${ }^{76}$.

\subsubsection{El problema de la delimitación del concepto. Origen y localización.}

Las teorías acerca del origen de los conceptos también han sido variadas.

Weisgerber y Whorf afirmaron que el concepto estaba ligado a la estructura de cada lengua, pero, en este caso, no habría conceptos sino significaciones ${ }^{77}$.

Heger $^{78}$ intenta resolverlo señalando la dificultad para conciliar la validez universal de los conceptos con el origen que tienen en una lengua dada. Esto no se prueba por un concepto aislado, sino a partir de las relaciones que los vinculan. Los conceptos no se pueden clasificar, son subjetivos, se desprenden de la significación que está condicionada por el sistema de una lengua dada:

- en la primera metalengua: en la formación de los conceptos en la lengua hemos de suponer una fase intermedia con conceptos precientíficos no fijados intensionalmente;

${ }^{73}$ Como revelan las investigaciones realizadas por F. Lounsbury sobre los términos de parentesco en Pawnee, el subsistema léxico de estos términos parece muy apto para un análisis estructural en general y un análisis componencial en particular. Basándose en una subdivisión de los diversos términos de parentesco en componentes, se pueden describir con exactitud las relaciones de parentesco acostumbradas en la respectiva comunidad hablante. El interés con que han sido acogidas estas tentativas por la semántica estructural se explica por esta forma de análisis componencial, especialmente adecuado para formalizaciones ulteriores; cf. G. Wotjak, Investigaciones..., pp. 175-177.

${ }^{74}$ Sin lugar a dudas, tal tipo de análisis es muy susceptible a la crítica porque intenta hacer a las categorías lingüísticas más rígidas y absolutas de lo que son en realidad. Por otro lado, muchos linguiistas afirman que este análisis componencial es muy rígido, entre otros motivos porque el lenguaje muestra los datos necesarios para difuminar los nítidos límites categoriales en los que nos situamos, y porque existe una gran pugna entre las taxonomías de carácter técnico y las populares; cf. W. Labov, «The boundaries of words and their meaning» apud Ways..., pp. 340-373.

${ }^{75}$ A. R. Fernández et alii, Semántica..., pp. 36-38. Sobre la relación entre Whorf y Humboldt (teoría de campos y etnolingüística) puede consultarse el libro de R. L. Miller, The Linguistics Relativity. Principle and Neohumboldtian Ethnolinguistics, Mouton, La Haya, 1968.

${ }^{76}$ K. Heger, «Bases...», apud Teoria..., pp. 1-33.

${ }^{77}$ Sobre los trabajos de Dubois puede consultarse: Le Vocabulaire politique et social en France de 1869 à 1872, Larousse, París, 1962; y «Les Structures Linguistiques de la parentè et leurs perturbations dans le cas de démence et de schizopherénie», CaLex, 8 (1966), 1, pp. 47-69, entre otros.

${ }^{78}$ O. Duchacek, «Le Champ conceptuel de la beauté en français moderne», VoxR, 18 (1956), pp. $297-$ 323, versión reelaborada aparecida con el título «Joli-Beau» en Le Français Moderne, 29 (1961), pp. 263-284. 
- en la segunda metalengua: sólo se admiten conceptos científicos. Se ha de probar su independencia de la estructura de una lengua a partir de las relaciones que unen a varios conceptos entre sí (géneros, especies y subespecies).

Si el sistema de relaciones entre conceptos refleja una estructura coherente que asigna a cada concepto un lugar exclusivamente suyo en este sistema, está lograda la independencia exigida.

También es problemática la forma de delimitar el concepto que se pretende estudiar. Evidentemente, para los que parten del carácter subjetivo, esto no supone ningún problema. Se suele tomar una decisión de orden conceptual (elección de un concepto dado por otra disciplina - filosofía, sociología, etc.establecido de manera empírica y con un juicio subjetivo y arbitrario, no lingüístico). Así, entre otros, destacan los trabajos de Dubois sobre el vocabulario político y social $^{79}$, de Duchacek sobre la belleza en el francés moderno ${ }^{80}$, de Geckeler sobre la edad ${ }^{81}$, de Greimas sobre la espacialidad ${ }^{82}$, de Lehrer sobre la $\operatorname{cocción}^{83}$, de Mounin sobre la habitación ${ }^{84}$, de Pottier sobre los asientos ${ }^{85}$; y en España G. Salvador ${ }^{86}$, R. Trujillo ${ }^{87}$, C. Corrales Zumbado ${ }^{88}$, A. Escobedo ${ }^{89}$, I. Corrales Zumbado $^{90}$, M. del M. Espejo Muriel ${ }^{91}$, M. A. Pastor Millán ${ }^{92}$, I. Rey Rodríguez ${ }^{93}$, y J. R. Lodares Marrodán ${ }^{94}$, entre otros.

${ }^{79} \mathrm{H}$. Geckeler, «Aplicación de nuestro método al campo léxico de los adjetivos de la edad en francés contemporáneo» apud Semántica..., pp. 304-330.

${ }^{80}$ A. J. Greimas, Semántica..., pp. 52 y ss.

${ }^{81}$ A. Lehrer, «Semantic cuisine», $J L, 1$ (1969), pp. 39-55.

${ }^{82}$ G. Mounin, «Essai sur la structuration du lexique de l'habitation», CaLex, 6(1965), pp. 9-24; también puede consultarse su estudio «Un champ sémantique: la dénomination des animaux domestiques», Langages, 1 (1965), pp. 31-54; (traducción en Semántica..., pp. 118-148).

${ }^{83}$ B. Pottier, Recherches sur l' analyse en linguistique et en traduction mecánique, Nancy, 1963, pp. 34 y ss.; traducción en Filología..., pp. 116 y ss.

${ }^{84}$ G. Salvador, «Estudio del campo léxico 'arar’ en Andalucía», Archivum Oviedo, 15 (1965), pp. 73-111 (tb. en Semántica y lexicología del español, Paraninfo, Madrid, 1984).

${ }^{85} \mathrm{R}$. Trujillo, El campo semántico de la valoración intelectual en español, Universidad de la Laguna, la Laguna, 1970.

${ }^{86}$ C. Corrales Zumbado, El campo semántico 'dimensión' en español, Aula de Cultura del Cabildo Insular de Tenerife, Santa Cruz, 1977.

${ }^{87}$ A. Escobedo, «Estructura funcional del campo hablar en español», RSEL, 10 (1980), pp. 113-134.

${ }^{88}$ I. Corrales Zumbado, El campo semántico 'edad' en español, Universidad de la Laguna, la Laguna, 1981.

${ }^{89}$ M. del M. Espejo Muriel, Los nombres de los colores en español, Universidad de Granada, Granada, 1990.

${ }^{90} \mathrm{M}$. A. Pastor Millán, Indagaciones lexemáticas: A propósito del campo léxico 'asir', Universidad de Granada, Granada, 1990.

${ }^{91}$ I. Rey Rodríguez, El camposemántico de lavaloraciónestéticapositivaenespañol(siglos XII-XIX),Universidad Complutense, Madrid, 1988.

92 J. R. Lodares Marrodán, El campo léxico MUJER en español, Universidad Complutense, Madrid, 1988.

${ }^{93}$ Se suele considerar a Trier el primer sistematizador de esta teoría; cf. J. Trier, Der deutsche Wortschatz im Sinnbezirk des Verstandes, Heidelberg, 1931.

${ }^{94}$ Se comprende que bajo esta afirmación permanece implícita la idea saussureana de lengua como sistema que, sin lugar a dudas, Trier llevó al vocabulario concibiéndolo, como hemos dicho, como una totalidad semánticamente articulada, estructurada en campos léxicos. 


\subsubsection{La delimitación de campos.}

La concepción de la agrupación de los significados atendiendo a sus componentes permitió la elaboración de la teoría del campo léxico por parte de Trier ${ }^{95}$. Para él, el léxico de una lengua está constituido por un conjunto jerarquizado de grupos de nombre ${ }^{96}$ (o campos léxicos) que recubren exactamente un dominio bien delimitado en el nivel de las nociones ${ }^{97}$ (o campos conceptuales). Cada uno de estos campos (tanto léxico como conceptual) está formado por unidades yuxtapuestas como las piedras irregulares de un mosaico.

Sus trabajos giraron en torno al vocabulario alemán del conocimiento, y extrajo las siguientes conclusiones:

- la existencia anterior a la estructura linguística formal de una organización no lingüística de la experiencia;

- la totalidad del léxico es una jerarquización de los campos léxicos sin lagunas ni encabalgamientos;

- un nombre toma significado por oposición con las otras unidades del mismo campo.

Para comprender bien la teoría de Trier podemos compararla con la concepción opuesta: la teoría de la copia, según la cual, la conciencia sería la interiorización del mundo exterior, sin que éste último se modifique en esta aproximación. Las ideas, que preexistían a los nombres, sólo son reflejos del mundo real ${ }^{98}$. El léxico sería reflejo directo de esas ideas, explicándose las diferencias entre las lenguas como una diferencia de grado en el reflejo de lo real.

Trier no negaba el mundo real, pero creía que el lenguaje debía dar una representación de la realidad, pues la organización de lo real no era la realidad misma; de hecho, cada lengua crea una imagen de la realidad. Para Trier tenía valor el que la visión del mundo impuesta por un lengua procediese de una matriz estructural en función de la cual eran ligados o diferenciados, comparados y opuestos, los datos de la realidad ${ }^{99}$.

${ }^{95}$ Adviértase que Trier distingue ambos campos; sin embargo, como ya se ha mencionado, se trata de designaciones distintas, según la perspectiva adoptada, para referirse a lo mismo. Con todo, para Trier, el campo conceptual es el de las organizaciones producidas en el pensamiento, y el campo léxico el de las producidas en la lengua.

${ }^{96}$ Tal afirmación ha llevado a muchos lingüistas a preguntarse sobre la posibilidad de concebir a priori un campo conceptual. Öhman lo ha estudiado verificando el caso de los canadienses que, habituados desde siempre a medir las distancias en millas, se encuentran con el sistema métrico y, aun conociendo las reglas de conversión de un sistema a otro, la mayoría sigue calculando según el modo tradicional. Lo que falta en estos casos del componente intelectual de la significación es una práctica social, una experiencia cotidiana de esas nociones; cf. S. E. Öhman, «Numerical models of coarticulation», JACS, 41 (1967), pp. 310-320.

${ }^{97}$ Sobre Trier puede consultarse H. Geckeler, Semántica..., pp. 117-188; G. A. Gutiérrez López, Epistemología..., pp. 177-191; E. Coseriu, Principios..., pp. 36 y ss.; J. Lyons, Semántica..., pp. 235 y ss.; entre otros.

${ }^{98}$ Sobre la teoría de Coseriu acerca de los campos léxicos puede verse E. Coseriu, Principios..., pp. 210-242.

${ }^{99}$ Para lo que sigue puede consultarse C. Germain, La semántica funcional, Gredos, Madrid, 1986, pp. 77-95; y S. Gutiérrez Ordóñez, Introducción a la semántica funcional, Síntesis, Madrid, 1989, pp. 105-108, entre otros. 
Siguiendo a Trier, los lingüistas han desarrollado considerablemente el concepto y la metodología del estudio de los campos léxicos. La definición más acertada es la de E. Coseriu ${ }^{100}$, quien lo define como un conjunto de unidades léxicas que se reparten una zona de significación común.

Coseriu comienza haciendo una serie de distinciones previas: primero, entre palabra y cosa; dice que a veces es difícil distinguir el significado lingüístico del significado de las cosas; ello le permite diferenciar el lenguaje natural del científico; segundo: entre lenguaje y metalenguaje; el objeto del primero es la realidad no linguística, frente al segundo cuyo objeto es el lenguaje; en tercer lugar, dentro del lenguaje se decide por un estudio sincrónico; cuarto: hace la distinción entre discurso repetido (lo que aparece en una tradición lingüística proverbios, frases hechas...-) y técnica del discurso (los procedimientos de una lengua libremente disponibles); quinto: frente a la lengua histórica, cuyo objeto no es un solo sistema, sino un conjunto de sistemas lingüísticos - diasistema, podemos encontrar como objeto de estudio una lengua funcional, en la que sólo hay oposiciones y no diversidad; sexto: dentro de ella interesa el sistema pues la norma está constituida por usos impuestos socialmente y el sistema comprende lo objetivamente funcional (distintivo); y séptimo: frente a la designación se queda con la significación (obsérvese el esquema de la figura $\mathrm{n}^{\mathrm{o}}$ 8 en la que recogemos la significación en el marco de la teoría lingüística según E. Coseriu).

\section{COSAS}

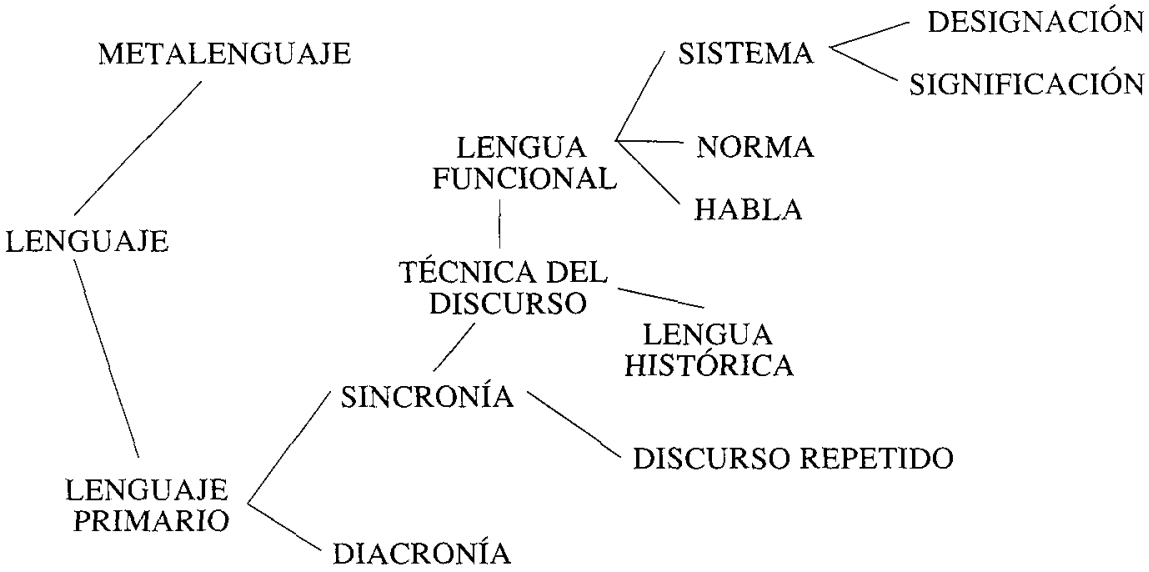

fig. 8: La significación en el marco de la teoría lingüística según E. Coseriu.

100 J. Dubois, «Recherches lexicographiques: esquisse d'un dictionnaire structural», ELA, 1 (1962), pp. $43-48$. 
Dentro de la significación, las unidades lingüísticas se organizan formando campos léxicos, cuyas características, según Coseriu, son las siguientes:

- Ios campos léxicos no son taxonómicos; es decir, no consisten en clasificaciones científicas de la realidad extralingüística;

- no son grupos de objetos colectivos;

- no son campos asociativos que se extienden sin control;

- son campos conceptuales (pero no al revés: los conceptuales no tienen por qué ser léxicos);

- están formados por los significados de sus unidades, los cuales se definen recíprocamente.

\subsubsection{El problema de la delimitación de las unidades del campo.}

Sobre este punto ha habido dos orientaciones fundamentales ${ }^{10 !}$.

\subsubsection{El criterio de la intuición.}

Destacan, entre otros, los ya mencionados trabajos de Trier, Dubois, Duchacek, y Lehrer.

Trier delimita el campo basándose en la afinidad de significados no reflejados por marcas formales.

Dubois construye un corpus escogido según el tema estudiado, y después aparta de él los términos técnicos de manera que sólo se retenga el vocabulario de la lengua común ${ }^{102}$.

Duchacek habla de la nominante semántica, de valores extranocionales que le permiten reagrupar gradualmente, del centro a la periferia, los términos en el campo conceptual de la belleza ${ }^{103}$.

${ }^{101}$ Las unidades más amplias de O. Duchacek se materializan en los campos linguíísticos de mots y de ideas. Los primeros abarcan los campos morfológicos y los sintagmáticos o sintácticos. Estos dos tipos de campos no son relevantes para un análisis de campos léxicos, pero sí los campos linguísticos de ideas que, a su vez, abarcan los campos conceptuales y los campos semánticos; (cf. O. Duchacek, «Beauté...», pp. 297-323).

La investigación de un campo semántico en la línea de Duchacek es desde el punto de vista operacional imposible, pues metodológicamente aún no hay ninguna posibilidad de probar o descubrir una estructuración sistemática con miles de unidades funcionales; (cf. H. Geckeler, Semántica..., pp. 205-210).

Por lo que respecta a la concepción del campo conceptual, E. Coseriu, Principios..., pág. 36, afirma que Duchacek no considera sino la mitad de lo que pertenece a su campo, esto es, no opone «beauté» a la «laideur» (en realidad sólo incluye sinónimos pero no antónimos).

${ }^{102}$ Para todo ello puede verse la breve exposición descrita en M. Justo Gil, Fundamentos del análisis semántico, Universidad de Santiago de Compostela, 1990, pp. 27-28.

${ }^{103}$ Véanse su trabajos «A Semantic Analysis of the Pawnee Kinship Usage», Language, 32, 1 (1956), pp. 158-194; y «Analyse structurale des termes de parentè, Langages, 1 (1964), pp. 75-99. 


\subsubsection{Los criterios objetivos.}

La búsqueda de criterios objetivos para la delimitación de las unidades que integran los campos léxicos es mucho más difícil. Los autores han intentado encontrar la objetividad en criterios extralingüísticos, en definiciones lexicográficas, en series derivacionales, y en análisis distribucionales ${ }^{104}$.

Para los primeros, la delimitación de las unidades de un campo no siempre se basa en decisiones arbitrarias y lingüísticas; por ejemplo, las estructuraciones hechas por antropólogos, ya sean sobre los términos de parentesco, el vocabulario del color, los términos etnográficos, etc. Lounsbury, al hacer el análisis estructural de los términos de parentesco, se basa en un criterio no lingüístico, pero objetivo; a saber, el parentesco por pacto, y el parentesco según los grupos sanguíneos ${ }^{105}$. Lévi-Strauss, sin embargo, pretende descubrir el sistema lingüístico que permite el proceso comunicativo. Como consecuencia, ve que los contenidos de esas estructuras lingüísticas son también procesos comunicativos (las relaciones de parentesco son procesos comunicativos porque estas relaciones existen, porque sirven para comunicarse, pues permiten el intercambio de bienes, de palabras y de mujeres). Al conocer el funcionamiento y la estructura de la parcela lingüística lo aplica a las demás ${ }^{106}$. Sólo queda buscar el sistema lingưístico. Para ello, las estructuras linguísticas son los cimientos para recibir las estructuras que corresponden a la cultura en sus variados aspectos ${ }^{107}$.

Sin embargo, y por mucha fundamentación lingüística que Lévy-Strauss quiera darle, estas formas tienen una fundamentación histórico social que recibe los contenidos de la cultura; de ahí la crítica de Umberto Eco ${ }^{108}$, para quien los hechos observados por Lévi-Strauss no tienen por qué estar determinados por las estructuras lingüísticas.

\footnotetext{
${ }^{104}$ Sus ideas aparecen muy claras en su obra Antropología estructural, Eudeba, Buenos Aires, 1976.

105 Como todo antropólogo, el estructuralista toma por objeto la diversidad de las manifestaciones humanas, $y$ a levantar su inventario dedica una parte esencial de sus esfuerzos. Pero un método nuevo le permite, además, retomar la preocupación que los cláscicos tenían por la universalidad de lo humano. Sobre este doble aspecto puede consultarse D. Sperber, El estructuralismo en antropología, Losada, Buenos Aires, 1975.

106 U. Eco, La estructura ausente, Lumen, Buenos Aires, 1981, pp. 397-466.

${ }^{107} \mathrm{Y}$ este conocimiento, no sólo de los nombres sino también de las cosas, se plasma en las definiciones que aparecen en los distintos diccionarios. Bajo este término podemos entender tanto la acción de definir como el enunciado que hace explícito el contenido de la palabra. Tradicionalmente se han considerado dos tipos de definición: la de las palabras y la de las cosas, que se plasman en diccionarios de palabras y de cosas. Puede consultarse al respecto $J$. Rey-Debove, «La définition léxicographique: bases d'une typologie formelle», TraLiLi, V (1967), pp. 141-159; o el cuadro expuesto por J. Rey-Debove, Étude linguistique et sémiotique des dictionnaires français contemporains, Mouton, La Haya-París, 1971, pág. 254.

${ }^{108}$ I. D. Apresyan, «Analyse distributionnelle des significations et champs sémantiques structurés», Langages, 1 (1962), pp. 44-74 (hay traducción española en Investigaciones semánticas, Nueva Visión, Buenos Aires, 1978, pp. 49-80).
} 
A veces con más razón, otras con menos, las investigaciones descansan en el postulado de que las estructuras léxicas no son más que un reflejo sin lagunas de estructuraciones de otro orden.

Los autores que han pretendido encontrar la objetividad en definiciones lexicográficas - Hjelmslev, entre otros - piensan que éstas son una base eficaz para estructurar el léxico, pero esto queda sólo en proyecto. Rey-Debove afirma que es posible acceder al sentido tanto por vía etnográfica como lingüística. Por tanto, no basta con conocer los nombres, sino que también hay que conocer las $\operatorname{cosas}^{109}$.

En tercer lugar, los que pretenden delimitar las unidades que integran los campos léxicos basándose en series derivacionales presentan una tendencia a la vez objetiva y linguística, que utiliza varios métodos:

- partir no de un concepto escogido arbitrariamente, sino del léxico de una lengua y reagrupar los signos según su afinidad formal. Pero esto es insuficiente, pues, según la arbitrariedad del signo, hay muchos nombres parecidos en cuanto a su significado y no en cuanto a su significante;

- la etimología: reúne las unidades de un campo basándose en el orden etimológico de las mismas.

El análisis distribucional de Apresyan ${ }^{110}$ es otro intento de delimitar objetivamente las unidades en el interior de un campo léxico. Apresyan cree que hay un defecto metodológico en Trier: el no liberarse de los métodos estructurales de la semántica tradicional. Para paliarlo, Apresyan ha utilizado una técnica de análisis a la vez objetiva y linguística que se fundamenta en el distribucionalismo

${ }^{109}$ Frente a la teoría mentalista (o interpretación psicológica del lenguaje, que tiene en cuenta la intervención del espíritu, de la voluntad o de la conciencia), el mecanicismo (o materialismo, cuya teoría predice las acciones de un individuo) de aspecto positivista, donde el lenguaje será únicamente una reacción a un estímulo, cobra auge. Se llega a la preocupación única por el aspecto formal del lenguaje. En esta línea destaca el distribucionalismo americano, cuyo padre, Harris, intenta la descripción linguística prescindiendo del contenido: bastará un inventario de elementos formales y unas reglas de distribución. Cf. sus obras Structural Linguistics, University of Chicago Press, Chicago, 1961, y Notes du cours de syntaxe, Seuil, París, 1976.

110 Muchos autores han criticado este modelo. Entre otros, Todorov expresa el principio de correspondencia biunívoca, según el cual una diferencia semántica puede no manifestarse por una sintáctica, pero la sintáctica es necesariamente reflejo de una semántica.

Dubois afirma que los campos semánticos deberían estar constituidos en sistemas para que los procedimientos estructuralistas fueran plenamente eficaces. Para ello toma como base la doble definición estructural de unidad significativa:

- la estructura paradigmática en la que la palabra se define como un sistema de relaciones establecido mediante oposiciones;

- La estructura sintagmática en la que la unidad léxica forma un sintagma nominal o verbal; cf. J. Dubois, «Recherches...», pp. 43-48. 
americano $^{1 !}$; así, la delimitación de los campos no reposa en ningún a priori conceptual; se apoya en la descripción distribucionalista de las significaciones de los nombres de la lengua. Se parte, pues, no de la significación misma del nombre sino de la distribución de su significación establecida formalmente. Se trata de atribuir a las unidades de una misma parte del discurso, figurando en el mismo contexto, una significación común.

Para aceptar este modelo habríamos de aceptar el postulado base por el que las propiedades gramaticales de los nombres son las que determinan su sentido, admitiendo la fórmula de Harris de que dos morfemas que tienen significaciones distintas difieren también en alguna parte de su distribución ${ }^{112}$.

\subsubsection{Modos de organizar las unidades en el interior de un campo.}

Una vez establecido el campo léxico, sea cual sea el criterio, lo que se nos plantea a continuación es el modo de organizar las unidades en el interior del campo. Hay distintas posturas para ello.

\subsubsection{Teoría de los encabalgamientos léxicos.}

Trier afirma que los elementos de un campo léxico son yuxtapuestos y recubren sin lagunas ni encabalgamientos toda la superficie conceptual correspondiente. Sin embargo, como dice Pottier, estas imbricaciones existen en la lengua y su presencia es definible gracias a los rasgos afines que presentan algunos semantemas entre sí $^{113}$. Como afirma Lyons ${ }^{114}$, se produce por lo que los estructuralistas describen como un hueco en el modelo (es decir, la ausencia de un lexema en un determinado lugar de la estructura de un campo léxico ${ }^{15}$ ). Son vacíos dispuestos a la lexicalización, que a veces pueden ser ocupados por palabras que amplían su sentido, pues las lenguas se adaptan a los cambios en las instituciones y prácticas sociales ${ }^{116}$.

${ }^{111}$ Cuando Pottier, por ejemplo, procede a la inserción de los sememas correspondientes a los lexemas silla, sillón, taburete, etc. muestra la presencia de ciertos rasgos que permiten la reunión de estas unidades, que presentan algo más que una simple afinidad global en el nivel de sus significados respectivos; gracias a estos rasgos existen encabalgamientos de unidades.

112 J. Lyons, «Semántica estructural y relaciones de sentido» apud Semántica..., pp. 283-287.

${ }^{113}$ Geckeler distingue tres tipos de vacíos léxicos: paradigmas defectivos, lagunas de subcategorización léxica (no todo concepto se manifiesta en las cuatro categorías de contenido absoluto) y lagunas en la estructuración lexemática (la lengua no dispone de significante lexemático para cada forma de contenido); cf. H. Gecleker, Semántica..., pp. 159-164; además puede verse C. Germain, Semántica..., pp. 101-103.

${ }^{114}$ Es lo que ocurre, por ejemplo, en el campo semántico de los medios de transporte, tal y como ha sido establecido, parcialmente, por Duchacek, en el que existe Ia intersección de los significados de bicicleta, motocicleta, automóvil, autobús, tranvia, trolebús, etc. Cf. O. Duchacek, «Sur le problème de l'analyse componentielle», TraLiLi, XI, 1 (1973), pp. 25-36.

115 G. Leech, «Componentes y contraposiciones de significados» apud Semántica..., pp. 115-146.

${ }^{116} \mathrm{Al}$ respecto puede consultarse su obra Essai d' une philosophie du siyle, A. Colin, París, 1968. 
Por tanto, podemos entender, como bien afirma Leech ${ }^{117}$, que las delimitaciones componenciales son borrosas por dos razones fundamentales: porque el lenguaje suministra los medios necesarios para difuminar los nítidos límites categoriales que nos encontramos en un nivel más tosco; y porque existe una pugna entre las taxonomías técnicas y populares.

\subsubsection{La hipótesis de Granger.}

Nos dice que un campo léxico debería consistir en una confrontación de varias organizaciones diferentes, en todo o en parte, de un mismo léxico ${ }^{118}$. Así, en el caso del léxico de la habitación de Mounin ${ }^{119}$, desde varios puntos de vista: construcción, ocupación, estética, etc ${ }^{120}$.

La preocupación principal de Granger se centra, por tanto, en el modo de estructuración de las unidades en el interior de un campo dado. Para determinar los diferentes puntos de vista que sirven de criterio de clasificación sugiere el recurso de lo que llama significaciones ${ }^{121}$. Comienza distinguiendo entre sentido y significado. Para él, sentido es lo que el modelo abstracto estructurado de un objeto o de un fenomeno transmite; y significado es lo que escapa a esa abstracción. La palabra manzana, por ejemplo, tiene un sentido: el concepto de «manzana», elaborado por la botánica; pero también tiene un significado: su relación con la experiencia individual vivida con las manzanas: si le gustan, si, por el contrario, su olor le recuerda el cloroformo, etc. Piensa que el análisis estilístico es el que tiende a establecer la posibilidad de una semántica propiamente dicha. De este modo, una vez que se han fijado los puntos de vista del análisis, propone confrontar las distintas organizaciones de un mismo léxico, organizaciones que corresponderán a varios puntos de vista del uso lingüístico ${ }^{122}$.

Por último, dice que la organización específicamente lingliística constituye una transición entre la organización muy abstracta de la sintaxis y la organización efectiva de las cosas ${ }^{123}$.

\subsubsection{Organizaciones simultáneas del sentido.}

Mounin atribuye las dificultades para estructurar el léxico al hecho de que la estructura de un campo está determinada a partir de puntos de vista diferentes que se encabalgan o dejan lagunas ${ }^{124}$.

117 G. Mounin, «Habitation...», pp. 9-24.

118 Como afirma repetidamente C. Germain, Semántica..., págs. 104 y 112, se trata, contrariamente a la hipótesis de Trier, de que las mismas piedras pueden figurar en diferentes mosaicos.

${ }^{119}$ Dicho en términos grangerianos, lo que resulta de la puesta en perspectiva de un hecho en el interior de una totalidad, ilusoria o auténtica, provisional o definitiva, pero en todo caso vivida como tal por una conciencia; cf. G. G. Granger, Essai..., pág. 11.

${ }^{120}$ Cf. G. G. Granger, Essai..., pág. 172.

${ }^{121}$ Un resumen de las ideas de Granger puede verse en C. Germain, Semántica..., pp. 104 y 109-116.

122 Cf. G. Mounin, Los problemas teóricos de la traducción, Gredos, Madrid, 1971, pp. 91-117.

123 E. Coseriu, «Hacia una tipología de los campos léxicos» apud Principios..., pp. 210-242.

${ }^{124}$ Cf. E. Coseriu, Principios..., pág. 235. 
Coseriu ${ }^{125}$ introduce la noción de dimensión para clasificar los campos (obsérvese la figura $\mathrm{n}^{\circ} 9$ en la que recogemos la clasificación de los campos léxicos de E. Coseriu atendiendo a su configuración ${ }^{126}$ ). El modo según el cual los lexemas están ordenados y la manera de acuerdo con la que se relacionan entre sí dentro de los campos depende del número de dimensiones semánticas que funcionan en el campo, y de los tipos formales de las oposiciones establecidas con respecto a estas dimensiones. Por ejemplo, en el campo léxico formado por los lexemas frío, caliente, templado..., la dimensión sería la temperatura.

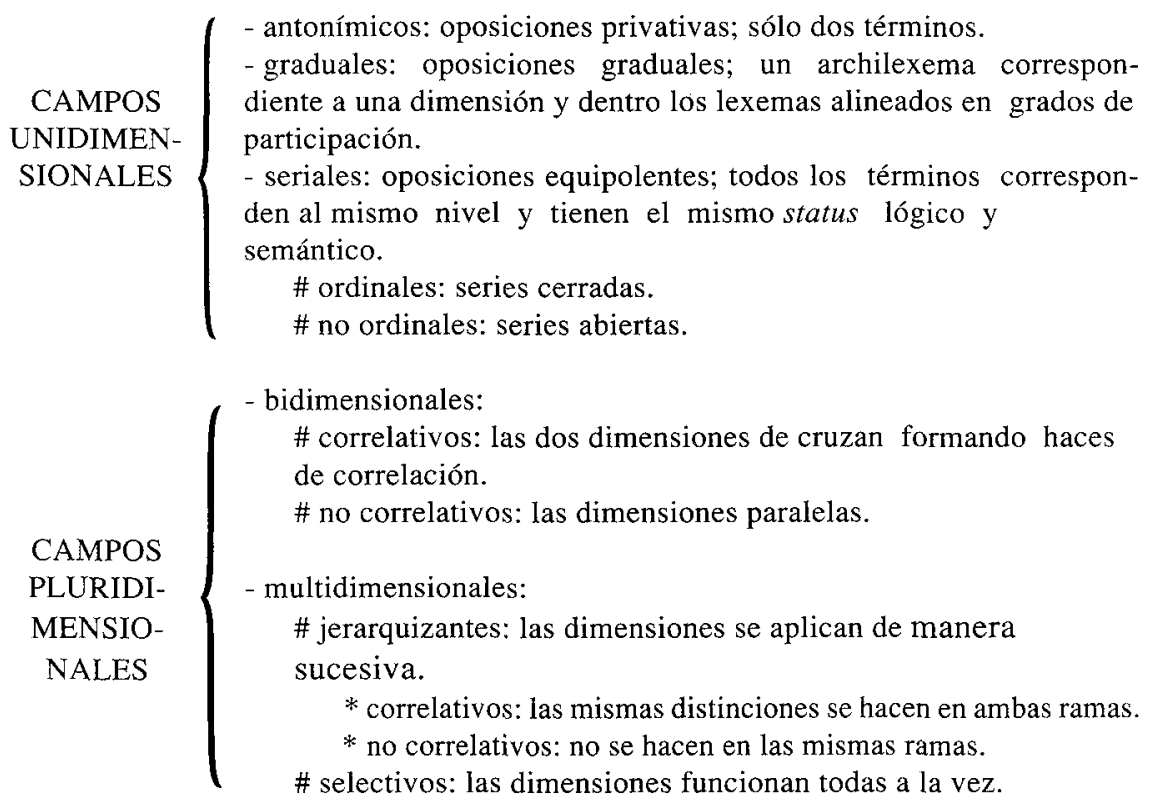

fig. 10: Clasificación de los campos léxicos según su configuración (E. Coseriu).

De todo lo expuesto anteriormente, podemos sacar las siguientes conclusiones:

- Desde el punto de vista paradigmático, los campos léxicos son análogos a los micro y macrosistemas fonológicos; podemos, pues, considerarlos como estructuras.

${ }^{125}$ E. H. Bendix, «The Data of Semantic Description» apud D. Steinberg y L. A. Jakobovits (eds.), Semantics. An Interdisciplinary Reader in Philosophy, Linguistics and Psychology, C.U.P., Cambridge, 1971, pp. 393-410.

${ }^{126}$ Su razonamiento se basa en la observación de que la mayor parte de los dominios léxicos estudiados hasta ahora forman grupos naturales privilegiados, poco representativos del léxico en general; cf. E. H. Bendix, «Analyse compositionelle du vocabulaire général», Langages, 20 (1970), pág. 104. 
- La tarea de la tipología de los campos será delimitar de manera sistemática esta diversidad de estructuración y establecer sus tipos y clases. Para ello, aquella debe fundarse en una clasificación de las oposiciones lexemáticas que se dan en el interior de un campo, y de las relaciones entre las mismas.

- La tarea concluirá intentando descubrir ciertos fenómenos que nos permitan observar una relación particular entre las distintas unidades (es decir, las relaciones sémicas que se dan entre los distintos lexemas que componen los campos léxicos).

\subsubsection{Relaciones de un campo con otros.}

Sería interesante, finalmente, estudiar la relación de un campo con otros. Trier sostiene que los campos léxicos se unen entre sí para formar campos de un nivel superior; éstos se unen a otros para formar nuevos campos a un nivel aún superior, y así hasta que todo el vocabulario esté estructurado. Para que esto sea posible, considera los campos como unidades cerradas, tanto léxica como conceptualmente.

Bendix ${ }^{127}$ está en contra de esto. Piensa que se puede entrar en el sistema semántico en un punto arbitrario ${ }^{128}$. Se propone analizar un conjunto de verbos en varios idiomas, escogiendo un pequeño número de verbos para formar un subconjunto de una red de oposiciones más amplias. Se ve obligado a no extraer de los verbos analizados más que los componentes semánticos que se desprenden de sus oposiciones mutuas sin tener en cuenta otros componentes que aparecerían si estos verbos estuviesen comparados con las otras unidades del conjunto al que pertenecen $^{129}$. Por ello, reconoce el carácter incompleto de sus análisis (aunque su postulado invalida el de Trier de los campos cerrados ${ }^{130}$ ).

127 E. H. Bendix, «Analyse...», pp. 101-125.

${ }^{128} \mathrm{C}$. Germain afirma que el hecho de poder entrar en el sistema semántico en un punto arbitrario no invalida, contrariamente a las pretensiones de Bendix, el postulado de Trier según el cual los campos constituyen entidades cerradas, aunque se manifiesta en contra de este postulado; cf. C. Germain, Semántica..., pág. 97.

${ }^{129}$ E. Coseriu, Principios..., pág. 241.

${ }^{130}$ Somos conscientes de que el problema - que es bastante general, no específico-consiste en que las disciplinas que se utilizan como fundamento explicativo de los modelos interdisciplinarios acaban por tomar naturaleza taumatúrgica, y el constructor del modelo, al creerlas (por ajenas) infalibles, no penetra en su meollo y tiende a creer en ellas, no a conocerlas. No son instrumentos, al fín; son, más bien, soluciones. Por ello, debemos insistir en la fundamentación metodológica que sustenta este trabajo en el marco globalizante de la interpretación dialéctica del significado, que organiza el trabajo realizado. Descripción Iinguíística y explicación literaria son dos niveles de acercamiento distintos, peto complementarios, que presentan una líneas de demarcación no muy nítidas, las cuales permiten el entrecruzamiento de distintas nociones (virtualidad/discursividad; sintagmática/paradigmática; significado del hablante/significado lingüístico) dentro de ellos, y que conforman, a la vez, dos procesos autónomos y en igualdad de condiciones de acercamiento al discurso literario. 
Coseriu, con su tipología de los campos léxicos bajo la forma de una estructura jerárquica, nos muestra la relación de dependencia de los campos y cómo un lexema funciona a veces en varios campos a la vez $z^{131}$.

\section{CONCLUSIÓN Y PROPUESTA METODOLÓGICA.}

En resumidas cuentas, un modelo aceptable de descripción semántica denotativa debe satisfacer las necesidades de la teoría semántica; dicho de otra forma, debe describir tanto las características de los significados (los significados de la lengua y los significados literales del hablante) como las relaciones entre los mismos.

Los principios en los que nos basamos para ello son los siguientes:

- Existe un significado lingüístico y un significado del hablante cuya diferencia se plasma en el aspecto creador del lenguaje. La teoría semántica estaría integrada por un componente lingüístico, que daría cuenta del significado lingüístico, y por un componente literario, que trataría del significado emotivo. La descripción y la explicación serían las técnicas preferentes para estos modelos.

- La significación está en relación con la palabra en sentido general (se trata de una formalización en el nivel léxico), y con la palabra en relación con un contexto (formalización en el nivel sintagmático). En nuestro caso, la teoría linguística daría cuenta del primero, y la teoría literaria de ambos ${ }^{132}$.

- Los signos lingüísticos poseen un significado denotativo y otro connotativo.

- El significado es descomponible en rasgos distintivos mínimos o componentes que se contraponen unos a otros.

- El significado integra conjuntos funcionales.

Teniendo en cuenta estas premisas ${ }^{133}$, el modelo que proponemos debe describir las características y las relaciones entre los significados.

${ }^{131}$ Obsérvese, tal y como recogemos en la figura $\mathrm{n}^{\varrho} 10$, que la construcción del modelo propuesto está fundamentada sobre las oposiciones que, partiendo de la saussureana lengua/habla, hemos desarrollado a lo largo del trabajo, a saber, significado linguístico/significado del hablante, descripción/explicación, significación en el nivel léxico/significación en el nivel sintagmático, entre otras.

${ }^{132}$ F. Meix Izquierdo, Dialéctica..., pp. 166-187.

${ }^{133}$ R. Trujillo, «Gramática, lexicología y semántica», RSEL, II, 1 (1972), pp. 103-109. 


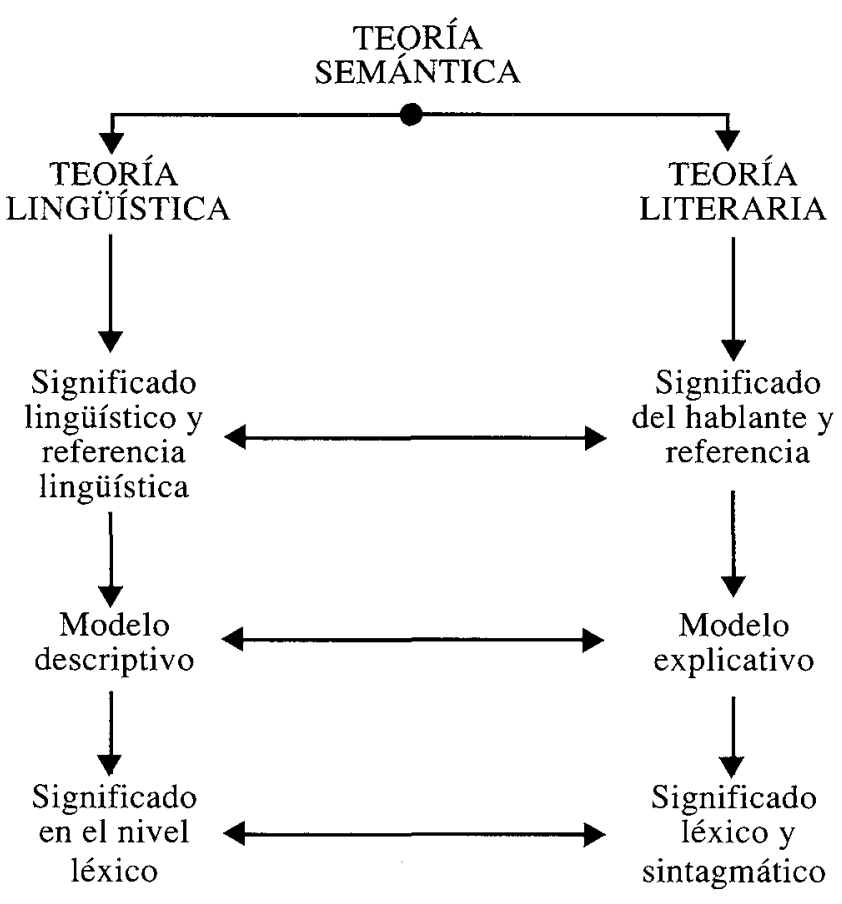

fig. 10: Premisas para la construcción de un modelo teórico que describa el significado denotativo.

\subsection{La dialéctica del significado lingüístico.}

La incapacidad técnica de la lingüística para explicar de forma satisfactoria la significación está en ignorar el carácter dialogístico de la lengua, al considerarla producto autosuficiente y ajeno a cualquier intencionalidad comunicativa. Pero, a pesar de este carácter formal, la lengua posee también un carácter psíquico; las estructuras de una lengua actúan eficazmente en la medida que son trascendidas por el sentido.

Como puede verse, forma y sentido se oponen y necesitan a la vez. La significación consistiría entonces en el movimiento contradictorio y renovado entre forma y sentido ${ }^{134}$. El significado sería la suma del sonido y de la evocación.

${ }^{134}$ Evidentemente, las categorías, los significados, etc. poseen fuzzy limits o límites borrosos, de modo que se ha llevado al núcleo de la teoría lo que antes eran excepciones. Sobre los límites borrosos y la teoría de los prototipos puede verse A. Vera, Las construcciones pronominales pasivas e impersonales en español, Universidad de Murcia, Murcia, 1990, pp. 59 y ss.; Ch. J. Fillmore, «An alternative to checklist theories of Meaning» apud Proceedings of the 1 st Annual Meeting of Berkley Linguistics Society, BLS, 1975, pp. 123-131; J. Lyons, Semántica..., pp. 254-257. 
Tal afirmación es la responsable del carácter heterogéneo e impreciso de las disciplinas del contenido. Trujillo ${ }^{13.5}$ define la semántica como la ciencia de la forma del contenido y su objeto sería tanto lo gramatical como lo léxico, pues ambos son formas del contenido. En cada unidad, la forma del contenido estará integrada por los rasgos diferenciales que la delimitan frente a otras en el nivel significante. La diferencia de expresión sería la prueba de tal rasgo. La forma, tanto en la gramática como en el léxico, está en el contenido y es la expresión la que nos permite reconocerla e identificarla como gramática o léxica. Por tanto, no podemos hablar de la semántica como algo distinto de la lexicología y la gramática porque supondría creer que la perspectiva formal es sólo la de la expresión, con lo que la semántica no sería una ciencia rigurosamente lingüística.

Tales afirmaciones nos llevan a establecer una primera oposición metodológica en el plano del significado para, posteriormente, estudiar sus posibles relaciones. Habrá de distinguirse entre unidades positivas y negativas.

\subsection{Características de los significados.}

\section{A/ ¿Cómo delimitar la estructura conceptual?}

Entre otros trabajos ya mencionados, el análisis de Pottier planteaba la cuestión de si se trataba realmente de un análisis de contenido lingüístico o de la descripción de una serie de objetos emparentados por su finalidad, o sea, de una sección de la realidad extralingüística. De hecho, Pottier partía de la descripción de los objetos, pero excluyendo los rasgos no relevantes y llegando así a un inventario de rasgos pertinentes. Sin embargo, los límites entre el punto de vista material y el punto de vista lingüístico son muy imprecisos. Por ejemplo, bueno y malo. Nocionalmente no se puede delimitar donde termina lo bueno y empieza lo malo. Se trata de unos límites en los que puede faltar la conciencia de subjetividades ${ }^{136}$. Por ello, proponemos delimitar el concepto teniendo en cuenta el propio carácter opositivo de la lengua ${ }^{137}$. Como sabemos, los signos no tienen valor por sí mismos sino en cuanto que se oponen unos a otros (es el carácter negativo, distintivo y opositivo, que dijera Saussure), y la oposición primaria es

135 Ya sabemos que las clasificaciones conceptuales se basan también en oposiciones y que éstas no son específicas de las lenguas (lo propio de ellas es la unión del significado y el significante). Aquellas se oponen primero como géneros (basándose en rasgos genéricos) y luego como especies (usándose diferencias específicas). Por tanto, la diferencia con el contenido semántico no es, pues, de orden instrumental, sino objetual: sólo es lingüístico en una lengua dada lo formalizado habitualmente en ella.

${ }^{136}$ No se trata, como puede pensarse a simple vista, de una forma sin substancia, al estilo glosemático. Lo marcado o lo positivo obedece a un criterio de valoración por el que el hombre reconoce la adecuación de los diferentes modos de ser de la realidad con la naturaleza de la realidad misma. Por el contrario, la negatividad se identifica con el reconocimiento de una disconformidad, inadecuación o discordancia en el sentido señalado; cf. M. J. Fernández Leboráns, Campo..., pág. 64.

137 J. L. Jiménez Ruiz, «Notas...», pp. 407-419. 
la misma oposición (+/-), marcas funcionales que son germen del inicio de la descomposición semántica ${ }^{138}$.

B/ Delimitación de las unidades del campo:

Consideramos el discurso como un sistema léxico total en el que se reagruparán los lexemas según su afinidad conceptual; dicho de otro modo, partiendo de la oposición primaria y, puesto que nocionalmente los límites entre los significados son poco precisos, partiendo del propio léxico habrán de agruparse los lexemas según características comunes que los emparenten y nos permitan integrarlos en campos léxicos.

C/ Organización de las unidades en el interior de un campo.

Se comprenderá que presentamos un modelo onomasiológico desde el momento en que pretendemos inventariar las oposiciones formadas por los signos paradigmáticos partiendo del concepto $(+/-)$ para llegar posteriormente a los significados.

Sin embargo, no nos quedaremos en ello, pues en el modelo literario que proponemos $^{139}$, seguiremos el camino de la explicación, es decir, desde los significados a los conceptos.

Para la definición de las unidades debemos utilizar los principales diccionarios ${ }^{140} \mathrm{y}$, según el planteamiento anterior, considerar el hecho de que la definición no puede partir de límites reales, puesto que definir consiste en delimitar separando los rasgos distintivos, partiendo de la lexía y no de la realidad. El proceso de definición será el siguiente:

- extraeremos del contexto lo que vayamos a definir;

- lo someteremos a un análisis;

- esa unidad léxica nos remitirá a un concepto (en primer lugar $+/-$ );

- analizaremos el concepto buscando conceptos menos complejos ${ }^{141}$.

A continuación, estudiamos los sectores positivo y negativo de los campos léxicos articulándolos en grupos funcionales, lo que nos aporta rigor y exactitud. Determinamos los semas a partir de oposiciones simples, numerándolos del uno en adelante como proponía Pottier (sin ignorar que los semas no son unidades independientes, y que sólo existen en función de su estructura). Para establecer

${ }^{138} \mathrm{Al}$ estar la lengua en continuo cambio, es aconsejable la utilización de las últimas ediciones. Por ello, remitimos a la novísima edición del Diccionario Actual de la Lengua Española, Biblograf, Barcelona, 1990, dirigida por el profesor Alvar Ezquerra, cuya redacción ha estado movida, principalmente, por un gran interés en reflejar la situación actual de la lengua española.

139 A. R. Fernández et alii, Semántica..., pp. 33-35.

${ }^{140}$ Sobre oposiciones semánticas puede consultarse: G. Leech, Semántica...,pp. 127-140; M. Bierwisch, «Semántica» apud J. Lyons, Nuevos horizontes de la lingüística, Alianza, Madrid, 1975, pp. 178-185; R. Trujillo, Semántica ..., pp. 185-190; L. Hjelmslev, Ensayos..., pp. 107-116; entre otros.

${ }^{141}$ Una aplicación práctica del modelo que proponemos puede verse en nuestro trabajo «La Rima III de Bécquer: descripción, explicación e interpretación», Asociación Europea de Profesores de Español, XVIII, n² 34-35 (1986), pp. 159-179. 
la estructura de esos grupos funcionales, estableceremos oposiciones dentro de ellos, oposiciones simples entre parejas de términos ${ }^{142}$. Tras ello, estudiamos las oposiciones atendiendo a los diferenciales y a las bases, lo que nos permite tener una base sólida y científica para el estudio de las relaciones entre los significados ${ }^{143}$.

\subsection{Relaciones entre los significados.}

Finalmente, el siguiente paso consiste en estudiar las relaciones entre los significados. Distinguimos dos tipos de relaciones:

- Relaciones microsemánticas: consideraremos en este apartado, por un lado, las relaciones sémicas entre aquellos sememas que ofrecen, para manifestarse lexicológicamente, lexemas distintos; $y$, por otro lado, las relaciones que ofrecen los semas que constituyen sememas cuya forma es idéntica.

- Relaciones macrosemánticas: en este apartado deben estudiarse las relaciones sémicas entre los distintos campos.

Finalmente, y para concluir, debemos añadir que esta descripción fenomenológica (objetiva) del significado lingüístico que hemos propuesto, no es suficiente para entender completamente el significado total de un campo léxico. Por ello, y para paliar estas deficiencias, la explicación trascendental (subjetiva) del significado emotivo de las unidades de los campos, y la interpretación dialéctica (hermenéutica del significado ${ }^{144}$ ), configuran el triedro metodológico capaz de aprehender coherentemente el enigmático y apasionante mundo del significado ${ }^{145}$.

${ }^{142}$ Efectivamente, el autor del texto no se comprende a sí mismo. Ni siquiera el autor vivo comprende su obra como totalidad. Sólo volviendo sobre la escritura, sobre los aspectos parciales de ella (denotación y connotación) se puede dar cuenta del producto linguístico. El explicar la obra es un acto en el que el autor dialoga consigo mismo a través de la objetividad que ha quedado presente en la escritura. Por ello, autor, texto e intérprete son elementos que deben tenerse en cuenta a la hora de aplicar la fórmula hermenéutica de «comprender mejor» y que se basa en los jalones expresados con anterioridad; cf. E. Lledó, El silencio de la escritura, Centro de Estudios Constitucionales, Madrid, 1991, pp. 78 y ss.

${ }^{143} \mathrm{Cf}$. J. L. Jiménez Ruiz, «La interpretación dialéctica del significado», Analecta Malacitana (en prensa).

${ }^{144}$ Efectivamente, el autor del texto no se comprende a sí mismo. Ni siquiera el autor vivo comprende su obra como totalidad. Sólo volviendo sobre la escritura, sobre los aspectos parciales de ella (denotación y connotación) se puede dar cuenta del producto lingüístico. El explicar la obra es un acto en el que el autor dialoga consigo mismo a través de la objetividad que ha quedado presente en la escritura. Por ello, autor, tex to e intérprete son elementos que deben tenerse en cuenta a la hora de aplicar la fórmula hermenéutica de «comprender mejor» y que se basa en los jalones expresados con anterioridad; cf. E. Lledó, El silencio de la escritura, Centro de Estudios Constitucionales, Madrid, 1991, pp. 78 y ss.

${ }^{145}$ Cf. J. L. Jiménez Ruiz, «La interpretación dialéctica del significado», Anlecta Malacitana (en prensa). 